\title{
Enzymatisch-elektronenoptische Analyse der Nucleinsäureverteilung, dargestellt an Escherichia coli als Modell
}

\author{
Von Dietrich Peters und Reinhard Wigand \\ Aus dem Bernhard-Nocht-Institut für Schiffs- und Tropenkrankheiten, Virusabteilung \\ (Direktor: Prof. Dr. E. G. N a u c k) \\ (Z. Naturforschg. 8 b, 180-192 [1953]; eingegangen am 31. Januar 1953)
}

Herrn Professor A. Buten andt zum 50. Geburtstag

\begin{abstract}
Das Fehlen ausgeprägt substratspezifischer Abbaumethoden setzte bisher der Elektronenmikroskopie biologischer Objekte recht enge Grenzen. Die Anwendung der durch hohe Selektivität ausgezeichneten Nucleasen, die lichtoptisch in steigendem Maße zu guten Erfolgen führen, war elektronenoptisch nicht von Nutzen, da nach Depolymerisation der Nucleinsäuren die massenmäßig überwiegenden Proteinanteile der Nucleoproteide liegen bleiben. Wird die „Schutzwirkung“ der Nucleinsäuren gegenüber peptischer Hydrolyse jedoch durch vorherige Einwirkung einer Nuclease aufgehoben, so kann das ursprünglich nicht wirksame Pepsin bei nachfolgender Anwendung proteolytisch wirken. Die Proteolyse läuft im Rahmen der durch die Nucleasewirkung vorgegebenen Spezifität ab, so daß eine selektive Aufhellung entsprechender Strukturen resultiert.

An Chabaud-fixierten Keimen von Escherichia coli aus der log-Phase ließen sich durch Kombination von Ribonuclease und Pepsin die Kerne, nach weiterer Behandlung mit Desoxyribonuclease und Pepsin völlig leere Membranen darstellen. Parallelversuche mit Giemsa- und Lichtgrünfärbung sowie mit dem Phasenkontrastverfahren zeigten, daß die elektronenoptischen Ergebnisse mit den lichtoptisch bereits gesicherten korrespondieren. Auf die Bedeutung der Wahl des Fixierungsmittels bei derartigen Untersuchungen wird hingewiesen.
\end{abstract}

$\mathrm{B}_{\mathrm{o}}^{\mathrm{s}}$ ei der elektronenoptischen Abbildung biologischer Objekte wird es bisher als besonders hinderlich empfunden, daß das erhaltene Kontrastbild kaum Hinweise auf die stoffliche Natur der dargestellten Strukturen zuläßt. Durch Verwendung von Eiweißfällungsmitteln wie z. B. Phosphorwolframsäure oder durch Anwendung von Osmiumtetroxyd lassen sich zwar bei einzelnen Objekten bessere Differenzierungen der Kontraste erreichen; die mit diesen Kunstgriffen erzielbaren Ergebnisse sind aber nur in wenigen Ausnahmefällen bedeutungsvoll. Den vielfach bewährten Färbemethoden der Lichtoptik hat die Elektronenmikroskopie z. Zt. noch nichts Gleichwertiges an die Seite zu stellen.

Der Natur der elektronenoptischen Bildentstehung entsprechend, liegt eine aussichtsreiche Entwicklung in der Anwendung chemischer und vor allem enzymatischer Agenzien. Das Ziel dieser Bemühungen muß es sein, bestimmte Anteile der Objekte selektiv herauszulösen und dabei die verbleibenden möglichst

1 A. Boivin, R. Tulasne, R. Vendrely u. R. M in ck, Arch. Sci. physiol. 1, 307 [1947].

2 B. P. K a u f m a n n, H. G a y u. M. M c D o$\mathrm{n}$ a ld, Cold Spring Harbor Sympos. quantitat. Biol. 14, 85 [1950]; J. cellular comparat. Physiol. 38, Suppl. 1, 71 [1951]. weitgehend in ihrer ursprünglichen Struktur zu erhalten.

Säuren und Alkalien allein, auch proteolytische Fermente wie Pepsin und Trypsin mögen in Einzelfällen befriedigend selektiv wirksam sein - generell sind sie es nicht. Dem steht die hohe Spezifität der $\mathrm{Nu}$ cleasen gegenüber. Wegen der großen Bedeutung, die man den Nucleinsäuren (NS) im Stoffwechsel der Zelle beimißt, hat es nicht an Versuchen gefehlt, die Enzyme Ribonuclease (R.) und Desoxyribonuclease (D.) der elektronenoptischen Methodik nutzbar zu machen.

Im Gegensatz zu den guten, allgemein anerkannten Leistungen dieser Fermente im Bereich der Lichtoptik (s. u.a. Boivin u. a. ${ }^{1}, \mathrm{Kaufmann} \mathrm{u.a.}{ }^{2}$, Catcheside und $\mathrm{Holmes}{ }^{3}$ ) verliefen entsprechende elektronenoptische Untersuchungen, die im wesentlichen an Bakterien durchgeführt wurden, enttäuschend. G re go i r e ${ }^{4}$ und kürzlich Kelle n ber ge ${ }^{5}$. beurteilten die Möglichkeiten einer Verwen-

3 D. G. C a t cheside u. B. Holmes, Symposia Soc. exp. Biol. 1, 225 [1947].

4 C. Gr é g o i r e, Proc. Conf. Electron Microscopy, Delft 1949, S. 161; Microscope électronique et recherche biologique, Liège-Paris 1950, S. 93.

5 E.Kellenberger, Experientia [Basel] 8, 99 [1952]. 
dung dieser Fermente für die elektronenoptische Untersuchung von Bakterien ausgesprochen negativ. Auch Bringmann ${ }^{6}$ konnte nicht über positive Resultate berichten.

Im Hinblick auf die chemische Wirkung dieser Fermente, die zwar NS depolymerisieren, nicht aber Eiweiß spalten, waren überzeugende Ergebnisse allerdings auch kaum zu erwarten. Bekanntlich überwiegt im allgemeinen der Proteinanteil der Nucleoproteide den Nucleinsäureanteil bei weitem ${ }^{7}$. Durch Herauslösung des letzteren ist bestenfalls mit einer geringen Aufhellung zu rechnen. Ist ein angreifbares Nucleoproteid aber - etwa wie u. U. im Cytoplasma - vergesellschaftet mit NS-freiem Protein, so ist der zu erwartende Erfolg noch geringer.

Unsere Untersuchungen richteten sich auf die demnach naheliegende Fragestellung, ob es möglich sei, die Nucleasen etwa durch eine nachfolgende Behandlung mit einer Protease, die normalerweise nicht hydrolysiert, doch noch als spezifisch wirkende Agenzien in die Methodik der Elektronenmikroskopie einzuführen. Um den Anschluß an bereits gesicherte Ergebnisse der Lichtoptik zu gewinnen, war dabei zu fordern, daß licht- und elektronenoptische Methoden schließlich zu korrespondierenden Ergebnissen führten.

Im Rahmen unserer Untersuchungen an Rickettsien $^{9}$, Haemobartonellen ${ }^{10}$ und Quaderviren ${ }^{11}$ entstand wiederholt der Wunsch, die Verteilung der NS einer näheren Analyse zu unterziehen. Umfangreiche Untersuchungen an Haemobartonella muris und Eperythrozoon coccoides ${ }^{11 a}$, über die wir demnächst ausführlicher berichten werden, hatten bereits grundsätzlich die Anwendbarkeit der hier dargestellten Methode ergeben. Da alle diese Organismen aber nur von der lebenden Zelle präpariert werden können und zudem wegen ihrer geringen Größe für lichtoptische Vergleiche nicht geeignet erschienen, unter-

(6 G. B ring m a n n, Zbl. Bakteriol., Parasitenkunde Infektionskrankh., Abt. I, Orig. 156, 547 [1951].

7 Boivin ${ }^{8}$ u. a. fanden bei Untersuchung von 4 E.coli-Stämmen bei $24 \mathrm{Stdn}$. alten Bakterien einen Gehalt von $3,8-4,4 \%$ DNS und $8,4-9,7 \%$ RNS, bezogen auf Trockengewicht.

8 A. Boivin, R. Vendrely u. R. Tulasne, Arch. Sci. Physiol.1, 35 [1947].

$9 \mathrm{~F}$. W e y e r u. D. P e t e rs, Z. Naturforschg. $7 \mathbf{b}$, 357 [1952].

10 E. G. N a u c k, D. Peters u. R. Wig and, Z. Naturforschg. 5 b, 259 [1950]; Z. Naturforschg. 6 b, 326 [1951].

11 D. Peters u. T. N a s e m a n n, im Druck.

11a R. W i g a nd u. D. P e ters, Physikal. Verhandlungen 3, 117 [1952]. nahmen wir entsprechende Modellversuche an einem leichter zugänglichen, größeren Objekt, nämlich Escherichia coli. Das Arbeiten mit Bakterien versprach auch insoweit Vorteile, als durch Wahl eines bestimmten Kulturalters einheitliche Resultate zu erwarten waren.

Diese Organismen sind von anderen Autoren lichtoptisch in ihrer Feinstruktur bereits gründlich untersucht worden. Für unser Vorhaben einer morphologischen Differenzierung von Ribo- gegenüber Desoxyribonucleoproteiden war es für die Wahl des Modells besonders bedeutungsvoll, daß über die Lagerung der desoxyribonucleinsäure(DNS)-haltigen Bakterienkerne $^{12}$ im ribonucleinsäure(RNS)-haltigen Cytoplasma unter den einzelnen Autoren Übereinstimmung bestand. Verschiedene lichtoptische Färbemethoden (Feulgensche Nuclealreaktion, HCl-Giemsa, Anwendung der Nucleasen u. a.) hatten zu identischen Ergebnissen geführt, die zudem eine Parallele in den phasenkontrastmikroskopischen Beobachtungen ${ }^{13}$ hatten. Demnach waren die beobachteten Kernstrukturen reell.

Wir beschränkten uns - wie auch viele andere Autoren - fast ausnahmslos auf Keime aus der logPhăse (3 Stdn. alte Kulturen), da die Bakterien in diesem Kulturalter bekanntlich noch recht groß sind und nach den Untersuchungen von $\mathrm{M}$ almgren und $\mathrm{Hedén}{ }^{14}$ (s. a. C a s pers s on u.a. ${ }^{15}$ ) neben dem Gehalt an DNS auch RNS noch in erheblicher Menge enthalten und da ihre Kerne besonders gut differenziert sind.

Hinsichtlich Größe und hohen RNS-Gehaltes wäre ein noch geringeres Alter der Keime (etwa 60 Min., Übergang von der log[Anlauf-]- in die log[Vermehrungs-]-Phase) günstiger gewesen. $\mathrm{Zu}$ diesem Zeitpunkt ist aber die Zahl der Keime zu gering, um bei der von uns verwendeten Abklatschtechnik zu genügend dichten Präparaten zu führen.

Um eine sichere methodische Grundlage zu erhalten, untersuchten wir recht eingehend die Einflüsse von Fixierung, $p_{\mathrm{H}}$ und anderen Milieubedingungen.

12 Mit der Bezeichnung „Bakterienkern“ schließen wir uns der in der angloamerikanischen und französischen Literatur seit Jahren gebräuchlichen Ausdrucksweise an unter den üblichen Vorbehalten hinsichtlich Morphologie und Physiologie. Andere Bezeichnungen (Nucleoide, Chromatinkörper, Chromosomen, Kernäquivalente u. a.) sind synonym.

13 H. K n öll, Zeiß-Nachr. 5, 38 [1944]; H. K n öll u. K. Z a p f, Zbl. Bakteriol., Parasitenkunde Infektionskrankh., Abt. I, Orig. 157, 389 [1951].

14 B. M a lmgren u. C. G. H e dén, Acta pathol. microbiol. scand. 24, 418, 448 [1947].

$15 \mathrm{~T}$. C a s pers son, B. M a lmgren, B. Thorell u. E. B j e rkelund, Nordisk Med. 28, 2636 [1945]. 


\section{Material und Methodik}

Ein beliebiger, aus menschlichem Stuhl isolierter Stamm von Escherichia coli wurde zunächst über drei Kulturpassagen geführt. Von einer $24 \mathrm{Stdn}$. alten Bouillonkultur wurden 2 Tropfen auf gewöhnlicher, 2,5-proz. Agarplatte ausgespatelt und $3 \mathrm{Stdn}$. bei $37^{\circ}$ bebrütet. Die Präparate wurden durch direktes Abklatschen mit gereinigten Deckgläsern für licht-, mit kollodiumbefilmten Platinnetzträgern für elektronenoptische Untersuchungen gewonnen. Nach 15 Min. Lufttrocknung bei Zimmertemperatur brachten wir sie ohne jede Waschung 15 Min. lang in die Fixierungsflüssigkeiten (Chabaud-, Carnoy-Gemisch 16), 96-proz. Äthanol, 4-proz. Formaldehyd, Methanol), spülten gründlich in Wasser und ließen die Präparate einheitlich 1 Stde. bei $60^{\circ}$ trocknen. Fixierung mit Methanol wurde nur bei lichtoptischen Präparaten angewendet, da es die Kollodiumfilme zur Auflösung bringen würde. Zur Hitzefixierung wurden ferner Präparate nach Lufttrocknung in den auf $105^{\circ}$ vorgeheizten Trockenschrank für 30 Min. - zum Teil länger - eingestellt. Zur Fixierung mit Osmiumtetroxyddampf brachten wir 2 Tropfen einer 1-proz. Lösung in einem Uhrgläschen auf die Agarplatte und fertigten nach 5 Min. langer Einwirkung die Abklatschpräparate an. Die Behandlung unfixierter Präparate begann ohne vorausgegangene Waschung etwa 15 Min. nach ihrer Herstellung, in einigen Versuchen nach 20-stdg. Lufttrocknung. Wir verwendeten durchweg kristallisierte Fermente:

1. $2 \times$ aus verd. Äthanol kristallisiertes Pepsin 17 der Worthington Biochemical Sales Co., Freehold, N.J. Dieses Präparat zeigte bei der elektrophoretischen Analyse eine Aufteilung in 2 Fraktionen von 68 bzw. $32 \% 11$.

2. $2 \times$ kristallisiertes Trypsin ( $50 \% \mathrm{MgSO}_{4}$ enthaltend) 18 (Worthingto n), das eine uncharakteristische elektrophoretische Uneinheitlichkeit zeigte.

3. Kristallisierte, salz- und proteasefreie Ribonuclease (R.) ${ }^{19}$ (Worthington). Die in der Elektrophoresezelle nach $\mathrm{T}$ is elius unter Verwendung einer Reflektionsoptik durchgeführte Analyse ergab auch bei diesem Ferment eine Aufteilung in mindestens 2 Fraktionen von etwa 57 bzw. 43\% (Abb. 1). Die Versuchsbedingungen waren:

$c=0,5 \%$, Michaelis-Puffer $p_{\mathrm{H}} 8,6, \mu=0,065,15,65 \mathrm{~mA}$, $9 \mathrm{~V} \cdot \mathrm{cm}^{-1}, 180 \mathrm{Min}$.

4. $1 \times$ kristallisierte Desoxyribonuclease (D.) 20 (Wo r t h i n g t o n), die elektrophoretisch nicht näher charakterisiert wurde.

Sämtliche Enzyme wurden in einer Konzentration von $0,02 \%$ angewendet. Pepsin wurde in $n / 100-\mathrm{HCl}$ gelöst $\left(p_{\mathrm{H}} 2\right) 21$, Trypsin in $m / 15$-Phosphatpuffer von $p_{\mathrm{H}} 7,5$, Ribonuclease und Desoxyribonuclease einerseits in dem glei-

16 Chabaud: $60 \mathrm{~cm}^{3}$ 80-proz. Äthanol,

$15 \mathrm{mg}$ krist. Phenol,

$5 \mathrm{~cm}^{3}$ 40-proz. Formaldehyd

$2 \mathrm{~cm}^{3}$ Eisessig.

Carnoy: $60 \mathrm{~cm}^{3}$ absol. Äthanol,

$30 \mathrm{~cm}^{3}$ Chloroform,

$10 \mathrm{~cm}^{3}$ Eisessig. chen Puffer, in der Regel aber in $m / 15$-Phosphatpuffer von $p_{\mathrm{H}} 6,0$ sowie in einigen Versuchen in dest. Wasser. Bei Verwendung von Wasser von $p_{\mathrm{H}} 6$ nahmen die Nucleaselösungen $p_{\mathrm{H}}$-Werte um 4,5 an. Die D.-Lösungen erhielten einen Zusatz von 0,005-m. $\mathrm{MgSO}_{4}$.

Die elektronenoptischen Objektträger wurden ganz in die Fermentlösungen eingelegt, für die lichtoptischen Untersuchungen brachten wir je einen Tropfen der Lösung auf die in feuchter Kammer befindlichen Deckgläser. Alle Fermente wurden bei $37^{\circ}$ angewendet. Die feuchte Kammer, die Ferment- und Kontrollösungen wurden vor Beginn der Behandlung auf diese Temperatur vorgewärmt. Vom gleichen Material wurden stets Präparate mit fermentfreien Kontrollösungen behandelt.

Die Einwirkungszeiten wählten wir möglichst kurz (in der Regel R. 10 Min., D. 20 Min., Pufferkontrollen 30 Min., Pepsin und Trypsin 30 Min.), um unspezifische Wirkungen auszuschalten (s. u.). Nach beendigter Einwirkung wurde

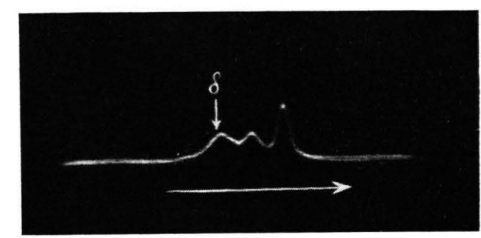

Abb. 1. Elektrophoretische Aufteilung der kristallisierten Ribonuclease (McDonald ${ }^{19}$ ), kathodische Wanderung, $\delta=$ Puffergradient.

mit dest. Wasser gründlich gespült, die elektronenoptischen Präparate nach Trocknung bei $60^{\circ}$ untersucht.

Die lichtoptischen Präparate wurden in der Regel nach G i e m s a gefärbt (Giemsa-Lösung Merck, 1 Tropfen auf $1 \mathrm{~cm}^{3}$ 0,01-m. Phosphatpuffer von $p_{\mathrm{H}} 7,2,30 \mathrm{Min}$.). Umkehrung der Deckgläser - Schichtseite nach unten - mit einer Wasserzwischenschicht zwischen Deckglas und tragendem Objektträger ergab bei der Betrachtung grundsätzlich gleiche, aber kontrastreichere Bilder, als wenn man die Deckglaspräparate mit der Schichtseite nach oben mit Immersion untersuchte. Das gleiche galt insbesondere auch für die Untersuchung mit dem Phasenkontrastmikroskop, wobei naturgemäß die Färbung unterlassen wurde. Weitere mit Lichtgrün (Hollborn) in 1-proz. Lösung 2 Min. lang gefärbte Präparate betrachteten wir nach kurzer Wasserspülung und Trocknung, um ein Ausziehen des Farbstoffes durch das Wasser zu vermeiden, aufrecht mit Immersion. Zur F e u l g e n schen Nuclealreaktion verwendeten wir Diamantfuchsin (M e r c k). Wir hydrolysierten 5-15 Min. in $n-\mathrm{HCl}$ bei $60^{\circ}$.

Die elektronenoptischen Untersuchungen wurden mit einem elektrostatischen Gerät (Typ EM 7) der S.D.L.

17 J. H. N or throp, J. gen. Physiol. 30, 177 [1946].

18 M. R. M c D on ald u. M. Kunitz, J. gen. Physiol. 29, 155 [1946].

19 M. R. M c D o n a l d, J. gen. Physiol. 32, 39 [1948].

20 M. Kunitz, J. gen. Physiol. 33, 349 [1950].

21 Sämtliche $p_{\mathrm{H}}$-Einstellungen wurden mit der Glaselektrode kontrolliert. 
(A E G / Zeiß) bei $45-50 \mathrm{kV}$, die lichtoptischen Aufnahmen mit einem Ultraphot (Zeiß), die Phasenkontrastbeobachtungen mit einem Instrument der Firma ZeißW i nkel durchgeführt. Schrägbedampfung erfolgte mit Palladium. Insgesamt musterten wir etwa 800 elektronenoptische Träger und 600 lichtoptische Präparate durch. Stets wurden 2 Deckgläser bzw. 3 elektronenoptische Träger gleichartig behandelt, und die Ergebnisse stimmten, auch bei Wiederholung der Versuche, von den zu besprechenden Ausnahmen abgesehen, in befriedigender Weise überein.

\section{Ergebnisse}

A) Morphologische Charakterisierung des $\mathrm{Stammes}$

Mit Hilfe einfacher Giemsa-Färbung gelang uns eine Abbildung der Kerne, die rotgefärbt auf hellblauem Plasmagrund ohne jede Differenzierung deutlich wie bei Protozoen hervortraten (Abb. $2^{*}$ ). Das Schwarzweißbild kann dabei nur einen unvollkommenen Eindruck vermitteln. Es zeigte sich das typische Bild einer jungen Kultur gramnegativer Bakterien: relativ große Organismen mit meist 2 bis 4 , bei ausbleibender Zellteilung auch mehr Kernen, die die Pole der Zellen freiließen. Die Gestalt der Kerne ist sicher nicht einfach rund, sie entspricht eher der von $\mathrm{Robinow}{ }^{22}$ beschriebenen Form quergestellter Hanteln. Besonders deutlich traten die Kerne bei Chabaud- und $\mathrm{OsO}_{4}$-Fixierung hervor, waren aber auch bei anderen Fixierungsmethoden erkennbar. Die Giemsa-Färbung bewährte sich demnach, wie schon von $\mathrm{Neum}$ an ${ }^{\mathbf{2}}$ beschrieben, als Methode zur metachromatischen Darstellung der Bakterienkerne. Sie fiel aber besonders in unbehandelten Präparaten oft regionär recht verschieden aus. Diese Differenzen beobachtete auch $\mathrm{Neumann}{ }^{23}$ und deutete sie als Ausdruck eines unterschiedlichen chemischen Aufbaues der Bakterien oder ihrer Membranen. Wir sind der Ansicht, daß vielmehr Zufälligkeiten in der Färbung, am Präparat haftende Agaroder Schleimreste usw. dabei von Bedeutung sind, und daß man von unterschiedlichem Aufbau der Bakterien nur dann sprechen kann, wenn in unmittelbarer Nachbarschaft verschieden gefärbte Keime zu sehen sind.

Mit Hilfe der Feulgenschen Nuclealreaktion erzielten wir eine nur sehr blasse Anfärbung der Kerne,

* Abb. 2-31, s. Tafeln S. 188, a-f.

22 C. F. R o b in ow, Proc. Roy. Soc. [London], Ser. B 130, 299 [1942]; J. of Hyg. 43, 413 [1944].

23 F. N e u m a n n, Zbl. Bakteriol., Parasitenkunde Infektionskrankh., Abt. II, Orig. 103, 385 [1940/41].

24 R. T u l a s n e, C. R. Séances Soc. Biol. Filiales 143, 1392 [1949]. die aber von den Kontrollpräparaten deutlich unterschieden war und vor allem in Parallele mit den anderen Färbemethoden als positive Nuclealreaktion aufgefaßt werden konnte. Úber Giemsa-Färbung nach $\mathrm{HCl}-\mathrm{Hydrolyse}$ wird weiter unten berichtet werden.

Bei Untersuchung frischer unfixierter Präparate im Phasenkontrastmikroskop zeigte sich der erstmalig von $\mathrm{Knöl1}{ }^{13}$ dargestellte typische Wechsel von hellen und dunklen Zonen. Der Vergleich mit dem gefärbten Präparat bestätigte die bekannte Tatsache, daß die hellen Bereiche den Kernen entsprechen. Sie zeigten die gleiche Zahl, Lokalisation und etwa die gleiche Form wie im Giemsa-gefärbten Präparat. Nach Chabaud-Fixierung erschienen die Bakterien im Gegensatz zum unfixierten Material praktisch unstrukturiert, im Unterschied zu den Befunden von Tulasn e ${ }^{24}$, der bei den von ihm untersuchten Stämmen keine Änderung des Phasenkontrastes nach Chabaud-Fixierung beobachtete.

Bemerkenswert ist, daß es kürzlich $\mathrm{S}$ chule ${ }^{25}$ gelang, die Kerne mit Acridinorange angefärbter lebender Bakterien im Fluoreszenzmikroskop zu beobachten, und zwar sowohl bei Präparation aus Kulturen wie auch aus natürlichem Substrat.

Elektronenoptisch waren die Bakterien unabhängig, von der Art der Fixierung völlig undurchstrahlbar und zeigten in dieser Hinsicht ein einheitliches Bild (Abb. 3). Öfters war an einem der Pole infolge geringer Retraktion des Cytoplasmas die Membran sichtbar. Bei einem zweiten Stamm von E. coli, den wir vergleichsweise untersuchten, waren Aufhellungen an den Stellen der Kernorte zu sehen, die eine gewisse Ähnlichkeit mit dem Bild im Phasenkontrastmikroskop hatten. Dies entspricht im Prinzip dem von Robinow und Cosslett ${ }^{26}$ an Pseudomonas, von $\mathrm{Hillier}$ u. a. ${ }^{27}$ sowie kürzlich von Ke ll en berge ${ }^{5}$ an E. coli dargestellten Verhalten. Die Durchstrahlbarkeit der Kernzone scheint demnach nicht nur von präparativen und apparativen Gegebenheiten ${ }^{\mathbf{2 7}}$, sondern auch stark von dem jeweils untersuchten Stamm abzuhängen.

B) Enzymatische Analyse nach Chabaud-Fixierung

bei $3 \mathrm{Stdn}$. alten Kulturen (s. a. Tab. 1, S. 185)

1. Trypsin. Nach 30 Min. langer Anwendung färbten sich die Bakterien nur noch schwach mit

25 R. S c hu le r, Naturwiss. 39, 90 [1952].

26 C. F. Robinow u. V. E. Cosslett, J. appl. Physics 19, 124 [1949].

27 J. Hilli er, S. Mu d d u. A. G. S mith, J. Bacteriol. 57, 319 [1949]. 
Giemsa-Lösung und erschienen im Phasenkontrastmikroskop stark aufgehellt. Bei elektronenoptischen Präparaten kam es ebenfalls zu einer Aufhellung unter völliger Herauslösung des Bakterieninhaltes mit Darstellung leerer Membranen (Abb. 4, 5). Bei längerer Einwirkung änderte sich der Befund nicht mehr.

Wendeten wir Trypsin statt in Phosphatpuffer von $p_{\mathrm{H}} 7,4-7,5$ in ionenarmem Milieu bei $p_{\mathrm{H}} 7,4$ an (Auflösung des $50 \% \mathrm{MgSO}_{4}$ enthaltenden Präparates in dest. Wasser und $p_{\mathrm{H}}$-Einstellung mit $\mathrm{NaOH}$ ), so war der $\mathrm{Ab}$ bau weit geringer (Abb. 6). Wir bestätigten damit die Bedeutung des Ionengehaltes der Lösung beim enzymatischen Abbau mit Trypsin, die $\mathrm{K}$ a u f m a n $\mathrm{n}$ u. a. 2 eindrucksvoll an Chromosomen demonstriert haben.

2. Pepsin. Nach Pepsinbehandlung - gelegentlich auch in Kontrollversuchen mit $n / 100-\mathrm{HCl}$ allein war die Intensität der Giemsa-Färbung in den Kernbereichen oft herabgesetzt, so daß Bilder ähnlich wie nach Behandlung mit D. entstanden (s. Abb. 16). Das Phasenkontrastbild änderte sich nach Pepsinbehandlung nicht. Elektronenoptisch ließ das Enzym die Keime in der weit überwiegenden Mehrzahl ebenfalls unabgebaut, jedoch zeigte stets etwa $1 \%$ der Keime uncharakteristische Aufhellungen. In Abb. 7 sind besonders viel abgebaute Keime dargestellt.

3. Hydrolyse mit $n$-HCl bei $60^{\circ}$. Die bekannte, von P i e k a r s ki ${ }^{28}$ eingeführte, von $\mathrm{R} \mathrm{o} \mathrm{b} \mathrm{i} \mathrm{-}$ now ${ }^{22}$ systematisch angewendete und von vielen weiteren Untersuchern für wertvoll befundene $\mathrm{Me}$ thode der HCl-Hydrolyse mit anschließender GiemsaFärbung führte zu regelmäßiger Darstellung der rotviolett gefärbten Kerne in fast ungefärbtem Cytoplasma, ähnlich wie in Abb. 9. Sämtliche Fixierungsarten waren hierfür gleichermaßen geeignet. Allerdings trat bei HCl-Hydrolyse gegenüber der Behandlung mit R. (s. u.) wahrscheinlich eine gewisse Schrumpfung ein, die auch $\mathrm{Hunter}$ u. a. ${ }^{29}$ beoḅachteten.

Die HCl-Hydrolyse führte im Gegensatz dazu nicht zu einer Kontraständerung im Phasenkontrastund Elektronenmikroskop. Hierin befinden wir uns in Úbereinstimmung mit mehreren Autoren $(\mathrm{T} \mathrm{u}$ la sne ${ }^{24}$, Kellenberge ${ }^{5}$ u. a.).

4. $n-\mathrm{HCl}$ und Pepsin. In Parallele zu den unten zu schildernden Versuchen mit Nucleasen lag es nahe, bei elektronenoptischen Präparaten im Anschluß an $n-\mathrm{HCl}$ noch Pepsin in $n / 100-\mathrm{HCl}$ einwirken

28 G. P i e k a r sk i, Arch. Mikrobiol. 8, 428 [1937].

29 M. E. Hunter, S. Mudd u. M. A. Woodburn, J. Bacteriol. 60, 315 [1950]. zu lassen. Tatsächlich kam es zu einer Aufhellung des Cytoplasmas und einer Darstellung der Bakterienkerne sowohl im Phasenkontrast- wie im Elektronenmikroskop (Abb. 8). Allerdings erschienen die Bakterienmembranen durch die Hydrolyse stark geschädigt. In Kontrollversuchen mit $n / 100-\mathrm{HCl}$ nach $n$ - $\mathrm{HCl}$ kam es nicht zu einer entsprechenden Aufhellung.

5. N u c le a s e n. Die nucleinsäurespaltenden Fermente - von B o ivin u. a. ${ }^{1}$ erstmalig auf Bakterien angewendet - hatten den bekannten charakteristischen Einfluß auf die Giemsa-Färbbarkeit der Bakterien. Nach Einwirkung von R. bei $p_{\mathrm{H}} 6$ färbte sich das Plasma nur noch zart rosa an, wobei die Zellgrenzen gut sichtbar blieben, und die Kerne stellten sich rotviolett gefärbt deutlich dar (Abb.9). Ließen wir D. einwirken, so waren die Kernzonen aufgehellt (Abb. 16), das Plasma hellblau gefärbt. Successive Einwirkung von R. und D. ließ die Bakterien nur noch ganz schwach rosa gefärbt erscheinen mit unregelmäßiger, undeutlicher Innenstruktur (Abb. 19). Hydrolyse mit $n$-HCl und anschließende D.-Einwirkung führte zu demselben Bild mit fast völligem Verlust der Giemsa-Färbbarkeit. Unsere Befunde stehen damit in guter Übereinstimmung mit den Angaben von Boivin u. a. ${ }^{1}$ und anderen Autoren, die zum Teil auch mit Chabaud-Fixierung gearbeitet haben.

Präparate, die sich nach Behandlung mit R. und D. nur noch schwach nach Giemsa anfärbten, ließen sich mit dem sauren Farbstoff Lichtgrün noch recht deutlich färben (Abb. 20), praktisch ohne Unterschied auch solche, die nur mit R. bzw. mit $n$ - $\mathrm{HCl}$ behandelt waren. Die Färbbarkeit war sogar deutlich besser als bei unbehandelten Präparaten, die ihrerseits nur eine sehr schwache Grünfärbung annahmen. Auf die Bedeutung dieses Verhaltens wird weiter unten hingewiesen werden.

Die Nucleasen hatten allein oder in Kombination angewendet keinen erkennbaren Einfluß auf den Phasenkontrast.

Elektronenoptisch führte R., 1 Stde. angewendet, bei einem Teil der Präparate zu einer geringen Plasmaaufhellung, so daß die Kerne als dunkle Verdichtungen schwach angedeutet erschienen. D. allein veränderte die Präparate nicht. Nach successiver Anwendung beider Nucleasen kam es zu einer etwas weitergehenden Aufhellung als nach $\mathrm{R}$. allein, die recht uncharakteristisch und im ganzen geringfügig war, in den Kontrollpräparaten jedoch fehlte. Hiernach besteht die Ansicht von Bringmann ${ }^{6}$, 
DeLamater und $\mathrm{Mudd}^{30}$ sowie Kellenb erger ${ }^{5}$, daß die Nucleasen lediglich eine Depolymerisation und überhaupt keine substantiellen Veränderungen zur Folge hätten, wohl nicht völlig zu Recht.

6. Nucleasen und Pepsin. Da Pepsin allein keinen Abbau zur Folge hatte, ließen wir es im Anschluß an die Nucleasen zusätzlich einwirken. Wir gingen hierbei von dem Gedanken aus, nach Abbau der Nucleinsäuren auf diese Weise den massenmäßig überwiegenden Proteinanteil der ursprünglich vorhandenen Nucleoproteide anzugreifen und damit zu einer elektronenoptisch sicher faßbaren Kontraständerung zu gelangen.

Mit R. und Pepsin behandelte Bakterien zeigten nach $\mathrm{G}$ i emsa-F ärbung Kerne, die gegenüber Behandlung mit R. allein (Abb.9) kleiner und weniger polymorph erschienen. Ihr Cytoplasma blieb völlig ungefärbt und von den Zellgrenzen war nichts mehr erkennbar (Abb. 10, in der Tabelle daher gestrichelt dargestellt). Dieses Verhalten ist im Vergleich zu dem elektronenoptischen Befund von besonderer Bedeutung. Auch mit Lichtgrün ließen sich die Kerne bei dieser Behandlungsart schwach gefärbt darstellen.

Behandlung mit D. und Pepsin und nachfolgende Giemsa-Färbung ergab die gleichen Bilder wie nach D. oder Pepsin allein (Abb. 16). Nach successiver Einwirkung von R., D. und Pepsin hatten die Keime ihre Giemsa-Färbbarkeit völlig verloren. Zugleich waren sie auch mit Lichtgrün nicht mehr färbbar.

Bei Paralleluntersuchungen im Phasenkontrastmikroskop gelang es, nach Einwirkung von R. und Pepsin, die beide für sich allein den Phasenkontrast nicht beeinflußten (s. o.), die Kernstrukturen in deutlich aufgehelltem Cytoplasma, entsprechend Abb. 9, sichtbar zu machen. Das umgekehrte Bild - aufgehellte Kerne in dunklem Cytoplasma, entspr. Abb. 16 - trat bei Behandlung mit D. und Pepsin in Erscheinung. Bei Anwendung von Pepsin nach R. und D. zeigten sich nur noch ganz schwach kontrastierte Bakterienhüllen, ähnlich wie nach Abbau mit Trypsin. Die Phasenkontrastbefunde verhielten sich damit den anschließend zu schildernden elektronenoptischen genau parallel.

Von besonderem Interesse war das Verhalten elektronenoptischer Präparate bei Kombination von R. mit Pepsin: Es traten nunmehr die Kerne in nahezu völ-

30 E. D. De L a mater u. S. Mudd, 5. Internat. Congr. Microbiol., Rio de Janeiro 1950, S. 30; Exper. Cell Res. 2, 499 [1951]. lig aufgehelltem Cytoplasma deutlich und mit großer Gleichmäßigkeit in allen Präparaten hervor (Abb. 11 bis 15). Ihre Lagerung und Struktur steht in guter Übereinstimmung mit dem lichtoptischen Bild (Abb. 9, 10). Vorherrschend ist die Zwei- bis Vierzahl der Kerne, die zum Teil wie gepaart aussehen, doch kommen sie in längeren Bakterien entspr. dem lichtoptischen Bild auch in größerer Zahl vor (Abb. 11). Wenn auch die Kernteilung in der Regel der Zellteilung

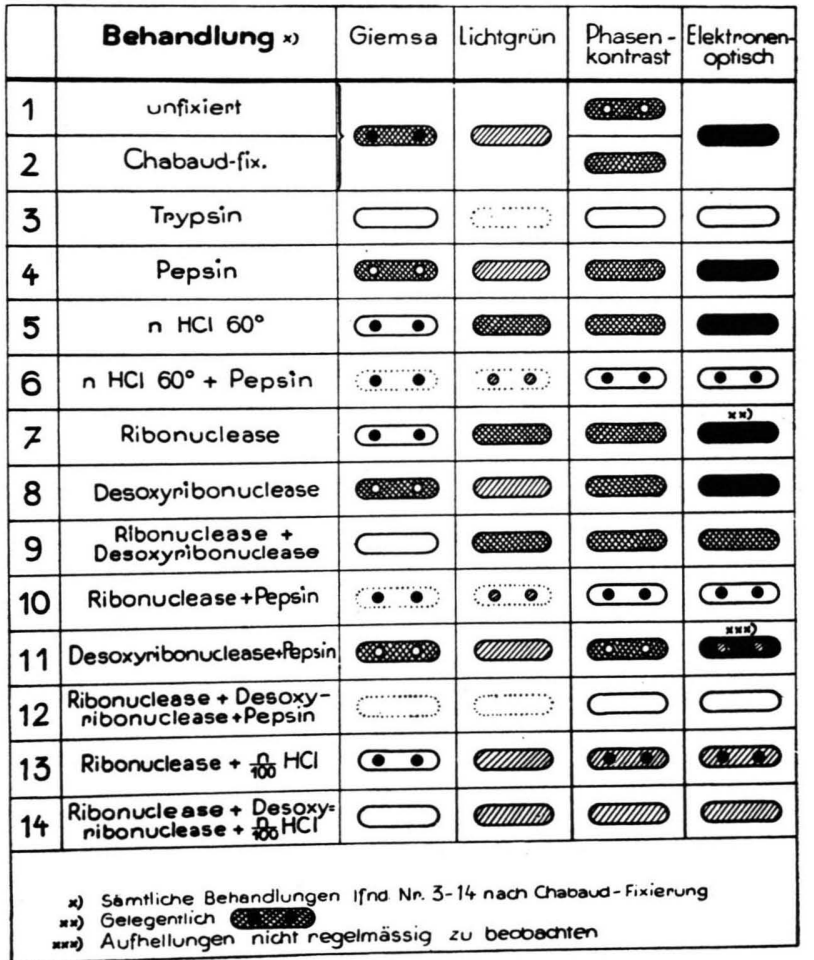

Tab. 1.

vorhergeht, so verbindet gelegentlich noch eine Kernbrücke zwei Zellen, die sich eben durchgeschnürt haben (Abb. 15). Manchmal sind sie zu einem längeren Gebilde „konfluiert“ (Abb. 13) oder erscheinen in Kettenanordnung verbunden (Abb. 11, 14).

Einige wenige Keime zeigten bei dieser Behandlungsart eine völlige Aufhellung. Vermutlich handelt es sich dabei um diejenigen, die bereits durch Pepsin allein abgebaut werden (s. o.).

Durch Behandlung mit D. war weiter zu zeigen, daß in den hier dargestellten „Kernen “ tatsächlich DNS lokalisiert ist. Ließen wir nach D. Pepsin einwirken, so bekamen wir öfters Strukturen wie in Abb. 17 und $18 \mathrm{zu}$ sehen, die an die von $\mathrm{Hillie} \mathrm{r}$ u. a. ${ }^{27}$ ohne Vorbehandlung dargestellten Keime er- 
innern: Die Kernorte sind offensichtlich aufgehellt und erscheinen bei Schrägbedampfung eingedellt (Abb. 18). In Lagerung und Gestalt entspricht das Bild etwa der Umkehrung von Abb. 12.

Es ist verständlich, daß diese Strukturen durch unterschiedliche Überlagerung mit Cytoplasmasubstanz nicht immer mit der gleichen Deutlichkeit zur Darstellung kamen. Aus dem gleichen Grund waren auch die entsprechenden lichtoptischen Ergebnisse weniger eindrucksvoll.

Ließen wir R., D. und Pepsin nacheinander einwirken, so ergab sich nunmehr eine völlige Aufhellung sämtlicher Bakterien mit Darstellung leerer Hüllen, zum Teil mit spärlichen, unregelmäßig granulierten Resten (Abb. 21, 22). Dasselbe geschah auch, wenn die Reihenfolge der Einwirkung von R. und D. vertauscht wurde. Die in den Abbildungen sichtbaren dichteren Zonen an den Polen sind, wie man Abb. 22 entnehmen kann, durch Faltenbildung der Membranen bedingt.

Vorhergehende Behandlung mit Pepsin behinderte einen anschließenden Abbau durch R. und Pepsin bzw. durch R., D. und Pepsin nicht. R. nach Pepsin angewendet, machte keine sicheren Veränderungen, D. nach R. und Pepsin ließ die Kerne etwas kleiner erscheinen.

7. Nucleasen und n/100-HCl. Als Kontrollen $\mathrm{zu}$ den vorgenannten Versuchen behandelten wir Präparate mit Nucleasen und anschließend mit $n / 100 \mathrm{HCl}\left(p_{\mathrm{H}} 2\right)$. Lichtoptisch trat bei Giemsa-Färbung nach Behandlung mit R. und $\mathrm{HCl}$ bzw. R., D. und $\mathrm{HCl}$ keine Änderung im Vergleich zur Behandlung mit den Nucleasen allein auf. Dagegen änderte sich der Phasenkontrast insofern, als nach R. und $\mathrm{HCl}$ deutlich Kerne in etwas aufgehelltem Cytoplasma sichtbar wurden und nach R., D. und $\mathrm{HCl}$ die Bakterien in toto partiell aufgehellt erschienen.

Dazu steht wiederum der elektronenoptische Befund in Parallele. Auch hier trat eine Aufhellung ein, die nicht so weit ging wie bei Anwendung von $\mathrm{R}$. und Pepsin. Die Kerne wurden nach Behandlung mit R. und $\mathrm{HCl}$ in unvollständig aufgehelltem Plasma mehr oder weniger deutlich sichtbar (Abb. 23). Bei D. und $\mathrm{HCl}$ war keine Kontraständerung zu konstatieren, was den Erwartungen entsprach, da ja auch Pepsin nach D. nur zu einer geringfügigen Aufhellung geführt hatte. Behandlung mit R., D. und $\mathrm{HCl}$ führte $\mathrm{zu}$ recht uncharakteristischer, unvollständiger Aufhellung der Bakterien (Abb. 24).

8. Pufferkontrollen. Selbstverständlich wurden licht- und elektronenoptisch stets Kontrolluntersuchungen mit entsprechenden fermentfreien Pufferlösungen durchgeführt. Bei längerer Einwirkung (60 Min.) von Phosphatpuffer vom $p_{\mathrm{H}} 6$ und 7,5 änderte sich die Giemsa-Färb- barkeit, und es kam teilweise zu Bildern wie nach Behandlung mit D. (s. Abb. 16). Das Phasenkontrastbild änderte sich in diesen Versuchen nicht.

Elektronenoptisch blieben Phosphatpuffer von $p_{\mathrm{H}} 6$ und 7,5 - 1 bis 2 Stdn. angewendet - mit Ausnahme einer geringen Konturunschärfe ohne Wirkung. Längere Zeit (18 Stdn.) angewendet, kam es dagegen zu starken, uncharakteristischen Aufhellungen.

Bei successiver Einwirkung von Pufferlösung und Pepsin - als Kontrollversuch zu den Nucleasen routinemäßig durchgeführt - zeigten sich nach längerer Dauer (je 1 Stde.) charakteristische Veränderungen in Form einer starken Retraktion des Cytoplasmas in weiter Membran (Abb. 25). Ob es sich hierbei nur um eine starke Schrumpfung oder um einen partiellen Abbau des Cytoplasmas durch Pepsin nach der Vorbehandlung mit dem Phosphatpuffer handelte, vermochten wir allein auf Grund der Kontrastwirkung nicht zu entscheiden.

Bei Anwendung von $n / 100-\mathrm{HCl}$ nach Phosphatpuffer trat nur eine ganz geringe Retraktion ein (Abb. 26).

9. Einflüssevon $p_{\mathrm{H}}$, Fermentkonzentration und Einwirkungszeit. Anwendung von R. bei $p_{\mathrm{H}} 7,5$ führte bei anschließender GiemsaFärbung allein unter Umständen schon bis $\mathrm{zu}$ fast ungefärbten Bakterien. In Parallele dazu zeigte bei anschließender Pepsineinwirkung elektronenoptisch ein Teil der Keime leere Membranen oder nur noch sehr kleine Zellkerne, während die Kontrolluntersuchung mit Phosphatpuffer von $p_{\mathrm{H}} 7,5$ die gleichen Veränderungen wie bei $p_{\mathrm{H}} 6$ (s. o.) ergab. Nach Anwendung beider Nucleasen in dest. Wasser $\left(p_{\mathrm{H}} u m 4,5\right)$ kam es nicht immer zu völliger Aufhebung der Kernfärbbarkeit und elektronenoptisch nach zusätzlicher Pepsineinwirkung nicht zu einem völligen Abbau der Kerne. Offenbar ist in diesem Fall der $p_{\mathrm{H}}$-Wert für D. bereits zu niedrig, während im ersten das alkalische Milieu, bei dem es ohnehin leichter zu unspezifischen Veränderungen kommen kann, ungünstig ist. Damit übereinstimmend haben auch andere Autoren ${ }^{1}$ meist in schwach saurem Bereich gearbeitet. Wir benutzten bei der Mehrzahl der Versuche Lösungen in $m / 15$ Phosphatpuffer von $p_{\mathrm{H}} 6$ mit stets reproduzierbaren und einheitlichen Ergebnissen.

Als Konzentrationen für Nucleasen und Pepsin wählten wir in der Regel $200 \gamma / \mathrm{cm}^{3}(0,02 \%)$. Es zeigte sich aber, daß alle drei Fermente unbeschadet ihrer Wirkung auf licht- und elektronenoptische Präparate um eine Zehnerpotenz verdünnt werden konnten (Abb. 11, 14, 15). R. wirkte auch bei 2 und $0,2 \gamma / \mathrm{cm}^{3}$ noch vollständig oder nahezu vollständig (Abb.27), 
ohne daß die Einwirkungszeit wesentlich gesteigert werden mußte, und selbst bei $0,002 \gamma / \mathrm{cm}^{3}$ war noch ein sicherer Einfluß nachzuweisen. Bei D. ließ die Wirkung bei $2 \gamma$ etwas nach, blieb aber ebenfalls bis zu $0,002 \gamma / \mathrm{cm}^{3}$ noch in geringem Umfang nachweisbar (Abb. 28). Bei Pepsin verminderte sich die Wirkung bei 2 und noch mehr bei $0,2 \gamma / \mathrm{cm}^{3}$ (Abb. 29) und war bei $0,02 \gamma / \mathrm{cm}^{3}$ nicht mehr sicher nachweisbar.

Man kann demnach in unserem Falle ohne weiteres mit Konzentrationen von $20 \gamma / \mathrm{cm}^{3}$ arbeiten. Bei noch stärkerer Verdünnung werden teilweise längere Einwirkungszeiten nötig. Es ist aber keineswegs gesagt, daß diese Bedingungen für alle entsprechenden Substrate geeignet sind. So scheint bereits bei andersartiger Fixierung oder bei älteren Keimen ein stärkerer Fermentangriff notwendig zu sein (s. u.). Man wird demnach für jedes neue Substrat die Bedingungen der optimalen Fermentaktivität erneut erarbeiten müssen.

Hinsichtlich der Einwirkungszeit stellten wir an elektronenoptischen Präparaten fest, daß R. bei $200 \mathrm{\gamma} / \mathrm{cm}^{3}$ bereits nach $1 \mathrm{Min}$. eine sichere Beeinflussung zeigte selbstverständlich nach folgender Behandlung mit Pepsin. Fast vollständig war der Abbau nach 5 Min., vollständig nach $10 \mathrm{Min}$. D. ließen wir gewöhnlich $20 \mathrm{Min}$. einwirken, da der Abbau von DNS nach den vorliegenden Mitteilungen 31 länger dauert als der von RNS. Eine längere Einwirkungsdauer ( 1 Stde.) hatte bei beiden Enzymen keinen zusätzlichen Effekt. Bei Pepsin war über 30 Min. hinaus lediglich bei Anwendung nach Phosphatpuffer von $p_{\mathrm{H}} 6$ bzw. 7,5 ein Unterschied in der Wirkung festzustellen.

Es sei erwähnt, daß die Chabaud-fixierten Membranen sich mit keinem der von uns angewendeten Fermente oder deren Kombinationen abbauen ließen.

\section{C) Fixierungseinflüs se}

Wenn wir als Maß für die Brauchbarkeit der Fixierungsmittel die Einheitlichkeit und das erwartungsgemäße Verhalten der Bakterien beim fermentativen Abbau annehmen, so zeigten sich fast gleichwertige Ergebnisse bei Fixierung mit $\mathrm{Ch}$ abaud-oder C a rn o y - Gemisch, und zwar sowohl licht- (GiemsaFärbung) wie elektronenoptisch. Lichtoptisch waren auch nach Fixierung mit 96-proz. Äthanol, Formalin und Methanol - jeweils 15 Min. lang angewendet brauchbare Ergebnisse zu erzielen. Orientierende elektronenoptische Untersuchungen bei Fixierung mit Äthanol und Formalin zeigten zwar ein einheitliches, im Prinzip gleiches Verhalten wie nach ChabaudFixierung, doch ließ der Erhaltungszustand der Kerne, bei Formalinfixierung auch der der Membranen, sehr zu wünschen übrig.

Bei hitzedenaturierten $\left(105^{\circ}\right)$ Präparaten ergaben sich im Gegensatz dazu nach kurzer Fermentbehand-

31 M. Ku nitz, J. gen. Physiol. 33, 363 [1950]. lung licht- und elektronenoptisch uneinheitliche Befunde, die nur zum kleineren Teil typischen Abbau nach R., R. und D. bzw. Nucleasen und Pepsin zeigten. Die Länge der Fixierung (30 bzw. 240 Min.) hatte auf dieses Verhalten ebensowenig Einfluß wie eine nach der Fixierung durchgeführte Waschung der Präparate. Nach längerer Fermenteinwirkung (Nucleasen 1 Stde., Pepsin 2 Stdn.) ging der Abbau weiter, und wir gelangten elektronenoptisch zu einigermaßen einheitlichen Resultaten. Doch auch hier trat die typische Lagerung der Kerne nach Behandlung mit R. und Pepsin nicht auf, und nach Einwirkung von R., D. und Pepsin enthielten die zudem stark geschädigten Membranen noch reichlich uncharakteristische Substanzreste.

Gingen wir von unfixierten Präparaten aus, so kam es sowohl licht- wie elektronenoptisch zu einem $\mathrm{Ab}$ bau, der hier aber stets zu völlig uneinheitlichen Präparaten führte. Die Behandlung mit R. und Pepsin brachte elektronenoptisch bei der Mehrzahl der Keime langgestreckte, oft spindelförmige Körper in leerer Plasmahülle (ähnlich wie in Abb. 30) ohne typische Kernanordnung zur Darstellung. Daneben zeigten sich unveränderte, uncharakteristisch aufgehellte Keime und leere Membranen. Auch nach R. und Giemsa-Färbung waren die Bilder uneinheitlich. Einwirkung von R., D. und Pepsin führte ebenfalls nicht bei allen Keimen zum Abbau bis zu Membranen (Abb. 30), die übrigens infolge der Behandlung stark geschädigt waren. Der weniger spezifische Einfluß von Trypsin trat dagegen auch bei unfixiertem Material weitgehend in Erscheinung. Bei den aufgehellten Keimen in Abb. 31 ist die Grenze des retrahierten Cytoplasmas noch sichtbar. Der Abbau geht also hier nicht so weit wie nach Chabaud-Fixierung (Abb. 4, 5). Die Membranen sind geschädigt, und ein Teil der Keime ist nicht oder nur unvollständig abgebaut. Ließen wir die Präparate vor der Behandlung $20 \mathrm{Stdn}$. an der Luft trocknen, so wurden alle Keime durch Trypsin gleichmäßig abgebaut. Hingegen war die Einwirkung von Nucleasen und Pepsin nach längerer Lufttrocknung nicht anders als bei nur kurzzeitig - 15 Min. - getrocknetem Material.

Nach Fixierung mit $\mathrm{OsO}_{4}-\mathrm{Dampf}-5 \mathrm{Min}$. lang war ebenfalls ein fermentativer Abbau möglich, jedoch mußten auch hier wie nach Hitzefixierung längere Einwirkungszeiten gewählt werden. Ähnlich wie bei unfixiertem Material zeigten sich licht- und elektronenoptisch völlig uneinheitliche Bilder, und nur bei einem kleinen Teil der Keime traten Kerne in 
Erscheinung. Die nach R., D. und Pepsin dargestellten Membranen waren wiederum schlecht erhalten und zeigten noch reichlich granulären Inhalt.

Aus diesem Vergleich geht hervor, wie ausschlaggebend die Wahl des Fixierungsmittels für derartige Untersuchungen ist. Wir stehen insofern in Einklang mit früheren Angaben, als auch dort das ChabaudGemisch am häufigsten zum fermentativen Abbau von Bakterien benutzt wurde (B o iv in u. a. ${ }^{1}$ u. a.). In zweiter Linie wurde Formalin bzw. Äthanol ${ }^{32}$ empfohlen. Bei Schnitten bzw. Gewebekulturen wurde besonders mit Carnoy-Gemisch gearbeitet ${ }^{2,33}$, während die sonst gebräuchliche Hitzefixierung verschiedentlich abgelehnt wird ${ }^{54}$. Wir können im Gegensatz zu Knaysi u. a. ${ }^{35}$ die Auffassung von Cat cheside und Holmes ${ }^{*}$ bestätigen, daß die Nucleasen auch bei unfixiertem Material arbeiten. Das gleiche gilt auch für Fixierung mit $\mathrm{OsO}_{4}$, wobei die Ansicht von Boivin u. a. ${ }^{1}$ sowie Winkler und $\mathrm{Knoch}^{36}$, daß dieses die Wirkung der $\mathrm{Nu}$ cleasen hindere, offensichtlich nicht in vollem Umfang zutrifft.

D) Orientierende Versuche an älteren Kulturen nach Chabaud-Fixierung

Einige Abbauversuche führten wir an 1 bzw. 4 Tage alten Kulturen 37 von E. coli durch mit der Fragestellung, ob die geschilderten Methoden auch auf diese anwendbar seien. Erschwerend war für die lichtoptischen Untersuchungen die geringere Größe der älteren Keime. Außerdem mußten wir wegen des bei weitem geringeren Gehaltes an NS 14 mit weniger charakteristischen Veränderungen durch die Nucleasen rechnen.

Erwartungsgemäß bestand bereits bei unbehandelten Präparaten eine gewisse Uneinheitlichkeit, indem nicht alle Keime elektronenoptisch völlig undurchstrahlbar waren und die im ganzen blassere Giemsa-Färbung nicht bei allen Bakterien gleichmäßig ausfiel.

R., D. und beide Nucleasen nacheinander änderten nur bei einem Teil der Keime die Giemsa-Färbbarkeit in der gewünschten Weise. Sie hatten keinen erkennbaren Einfluß auf elektronenoptische Präparate, auch nicht bei anschließender Einwirkung von $n / 100-\mathrm{HCl}$.

Pepsin war bei Chabaud-fixiertem Material nicht ohne Einfluß, vielmehr zeigte sich bei einem größeren Teil der Keime bereits ein Abbau in der Richtung, wie wir ihn in Verbindung mit Nucleasen beobachteten.

Kombination von R., D. oder R. und D. mit Pepsin

32 R. Tulasne u. R. Vendrely, C. R. Séances Soc. Biol. Filiales 141, 674 [1947].

33 R. J. S t e in u. H. W. G e rarde, Science [New York] 111, 256 [1950].

34 K. A. B is s e t, Internat. Rev. Cytol. 1, 83 [1952].

35 G. Knaysi, J. Hillier u. C. Fabricant, J. Bacteriol. 60, 423 [1950]. führte an elektronenoptischen Präparaten auch bei älteren Keimen zu einem Abbau. Er ging allerdings stets ungleichmäßig vor sich und trat - weniger weitgehend auch bei Behandlung mit Phosphatpuffer von $p_{\mathrm{H}} 6$ und Pepsin und sogar mit Pepsin allein ein. Einerseits nahmen demnach die unspezifischen Einflüsse bei älteren Keimen zu, andererseits wirkten die Nucleasen weniger vollständig und langsamer. Wir mußten mit $200 \mathrm{\gamma} / \mathrm{cm}^{3}$ je 1 Stde. lang arbeiten und erzielten trotzdem keinen erschöpfenden Abbau, indem z. B. nach R., D. und Pepsin nur ein Teil der Keime bis zu leeren Hüllen abgebaut wurde.

Die Ursache dieser erhöhten Fermentresistenz bei verminderter Resistenz gegenüber unspezifischen Einflüssen ist noch ungeklärt. Es hat den Anschein, daß die beobachteten Unterschiede zwischen jungen und alten Keimen Ausdruck eines Umbaues der Nucleinsäuren und der Proteine sowie ihrer Beziehungen zueinander darstellen.

Die Kerne selbst, soweit wir sie als solche bezeichnen dürfen, da sie in ihren Eigenschaften von denen junger Bakterien abweichen, kamen stets in der Einzahl als relativ große, längliche Gebilde parallel zur Längsachse des Bakteriums vor. Sie waren häufig durchstrahlbar.

Zwischen 1 und 4 Tage alten Kulturen fanden wir keine grundsätzlichen Unterschiede.

\section{Diskussion}

Tab. 1 gibt unsere Ergebnisse schematisch wieder, indem die lichtoptischen Befunde den elektronenoptischen gegenübergestellt werden. Der Unterschied in der Darstellungsweise wird dabei deutlich: Der $b a$ sische Giemsa-Farbstoff färbt intensiv nur NS-haltige Strukturen, das saure Lichtgrün relativ intensiv nur Proteine, vermutlich basische, die durch vorherige Depolymerisation der jeweiligen NS freigelegt worden sind. Die Abbildung mit dem Phasenkontrastverfahren ist demgegenüber in unserem Fall im wesentlichen ein Ausdruck der Masse, unspezifisch für den chemischen Aufbau, steht damit also in gewisser Analogie zur Elektronenmikroskopie. Ein Vergleich der phasenkontrast- und elektronenoptischen Ergebnisse zeigt, daß beide Verfahren - wie zu erwarten - im Gegensatz zu den Färbemethoden zu gleichsinnigen — nämlich massenspezifischen - Ergebnissen geführt haben.

Es muß ausdrücklich hervorgehoben werden, daß die in der Tabelle dargestellten Befunde sich nur auf junge Keime aus 3-stdg. Kultur beziehen. Diese Bakterien befinden sich im Zustand lebhafter Vermehrung (log-Phase) und haben mit Sicherheit einen an-

36 A. W ink le r u. M. K n o ch, Zbl. Bakteriol., Parasitenkunde Infektionskrankh., Abt. I, Orig. 157, 239 [1951].

37 Die Keime wurden hierbei von Schrägagarröhrchen gewonnen und aus dest. Wasser präpariert. 
D.Peters und R.Wigand, Enzymatisch-elektronenoptische Analyse der Nucleinsäureverteilung,

dargestellt an Escherichia coli als Modell (S. 180)

Escherichia coli, 3 Stdn. alt. Alle Präparate, mit Ausnahme von Abb. 30 und 31 sind nach Chabaud fixiert.

Trypsin $p_{\mathrm{H}} 7,5$, Nucleasen und Phosphatpuffer $p_{\mathrm{H}} 6$, Pepsin und $n / 100-\mathrm{HCl}, p_{\mathrm{H}} 2$. Fermentkonzentrationen, soweit nicht anders vermerkt, $200 \gamma / \mathrm{cm}^{3}$.

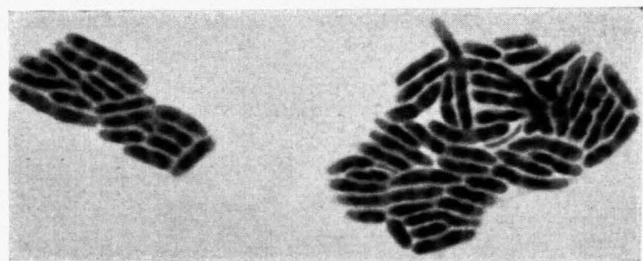

Abb. 2. Unbehandelt. Lichtoptisch, Giemsa: metachromatische Färbung, rote Kerne in hellblauem Plasma, $1500 \times$.

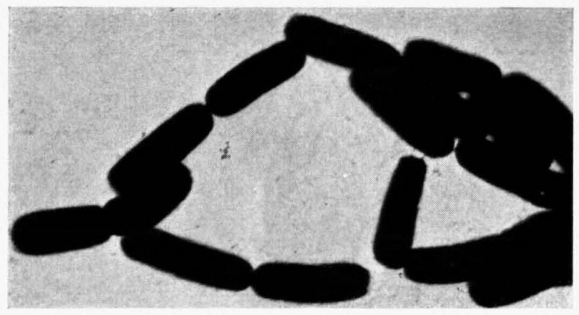

Abb. 3. Unbehandelt; undurchstrahlbar, an den Polen Membran sichtbar, $5000 \times$

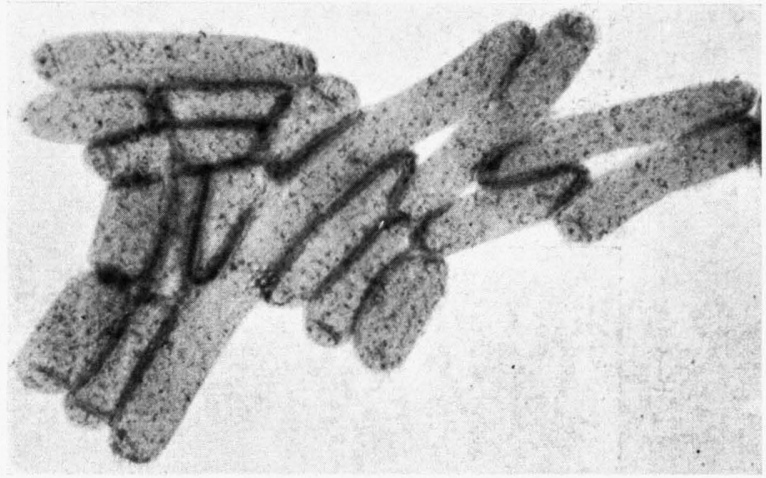

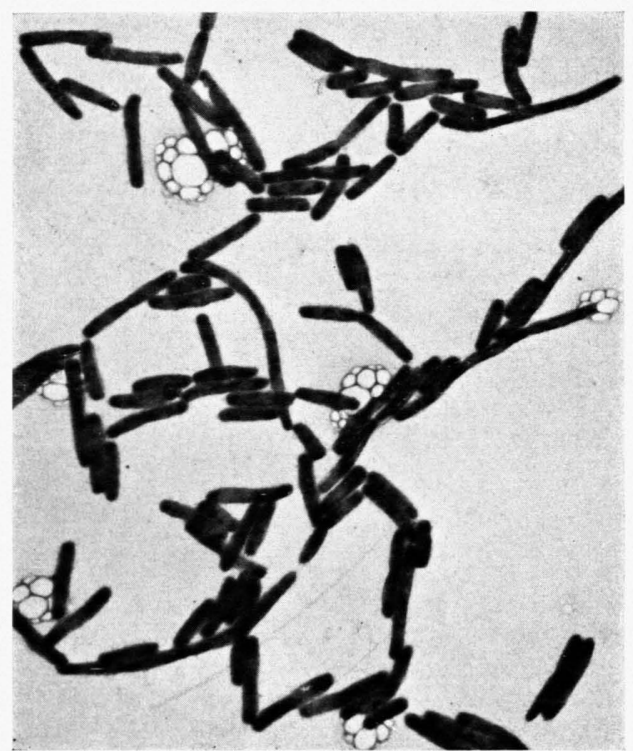

Abb. 6. Trypsin „ionenarm“; nur partieller Abbau, $2500 \times$.

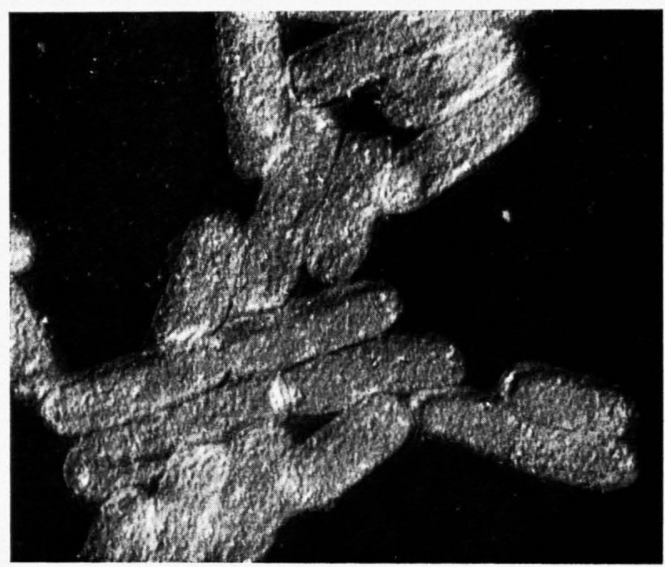

Abb. 4, 5. Trypsin. Leere Membranen, Abb. 5. Pd-b€dampft, 5000×. 


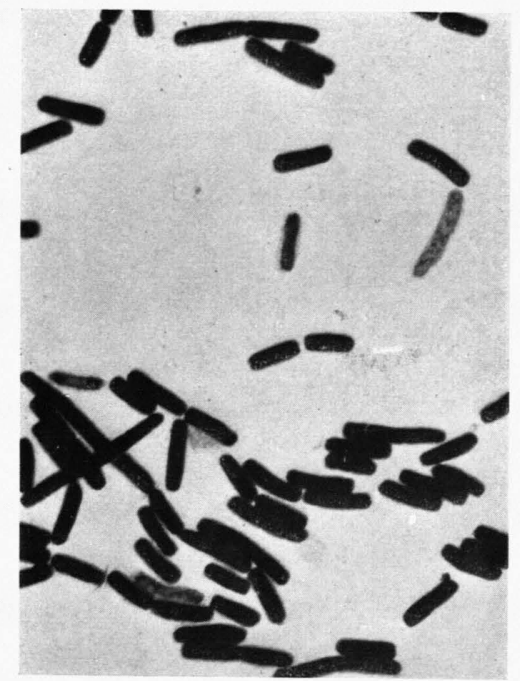

Abb. 7. Pepsin. Undurchstrahlbar; einzelne abgebaute Keime (zufällig besonders zahlreich), $2500 \times$.

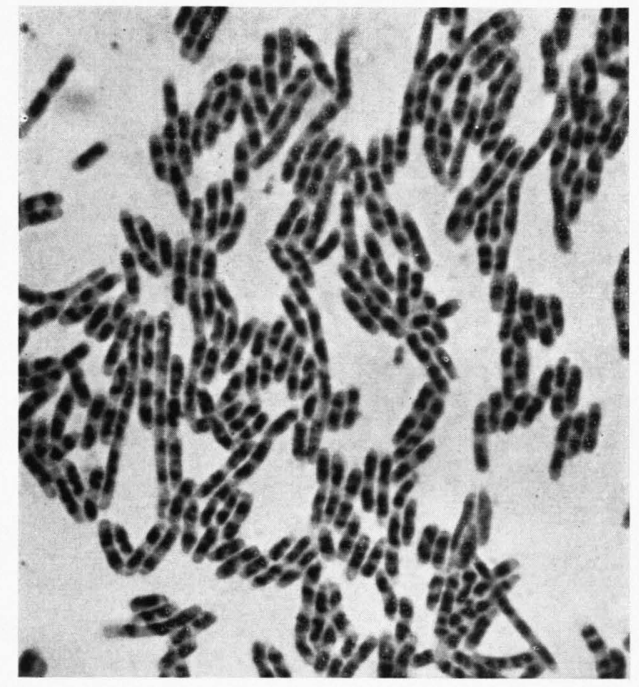

Abb. 9. Ribonuclease (R.). Lichtoptisch, Giemsa. Cytoplasma aufgehellt, Kerne deutlich, $1500 \times$.
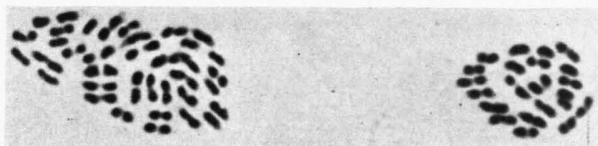

Abb. 10. R., Pepsin. Lichtoptisch, Giemsa. Cytoplasma völlig ungefärbt, Zellgrenzen nicht sichtbar, Kerne kleiner als in Abb. 9, 1500X.

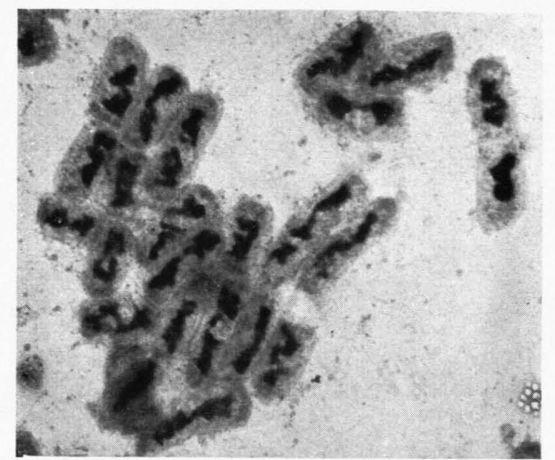

Abb. 8. $n$-HCl, 6 Min. $60^{\circ}$, Pepsin. Cytoplasma aufgehellt, Kerne deutlich, Membranen geschädigt, $5000 \times$.

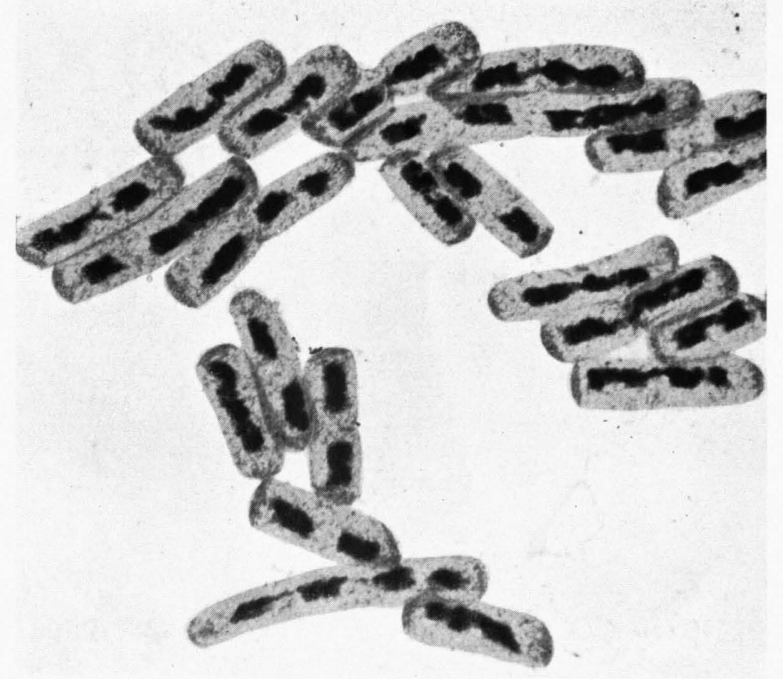

Abb. 12. R., Pepsin, 5000×.

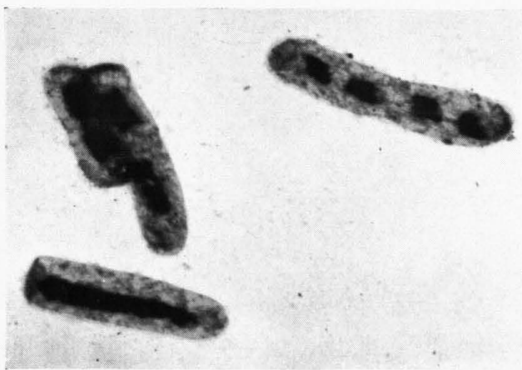

Abb. 13. R., Pepsin. „Konfluenz“ der Kerne bei einem Keim, $5000 \times$. 


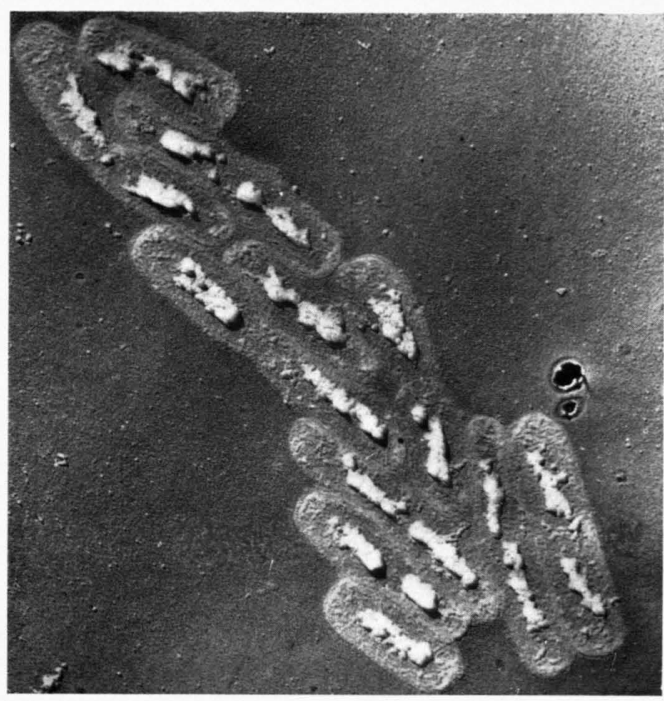

Abb. 14. R. $\left(20 \gamma / \mathrm{cm}^{3}\right)$, Pepsin, Pd-bedampft, $5000 \times$.

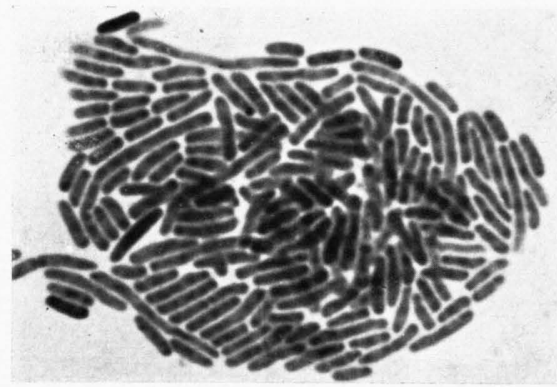

Abb. 16. Desoxyribonuclease (D.). Lichtoptisch, Giemsa. Kernzonen aufgehellt, Cytoplasma gefärbt, $1500 \times$.

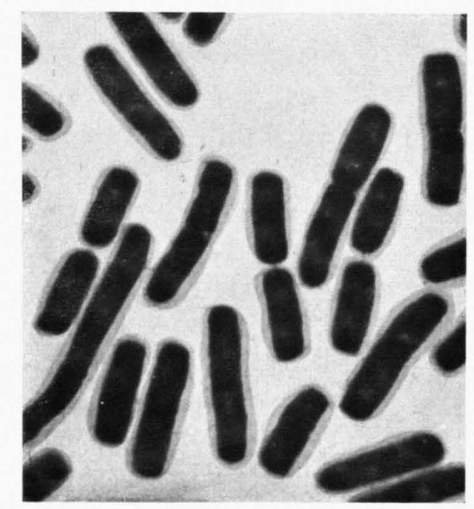

Abb. 17. D., Pepsin. Kerne aufgehellt, Cytoplasma retrahiert, Membran deutlich, $5000 \times$.

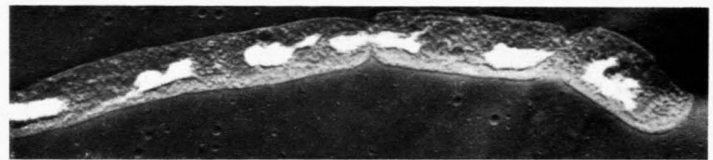

Abb. 15. R. $\left(20 \gamma / \mathrm{cm}^{3}\right)$, Pepsin $\left(20 \gamma / \mathrm{cm}^{3}\right)$. Zellteilung mit „Kernbrücke“, Pd-bedampft, $5000 \times$.
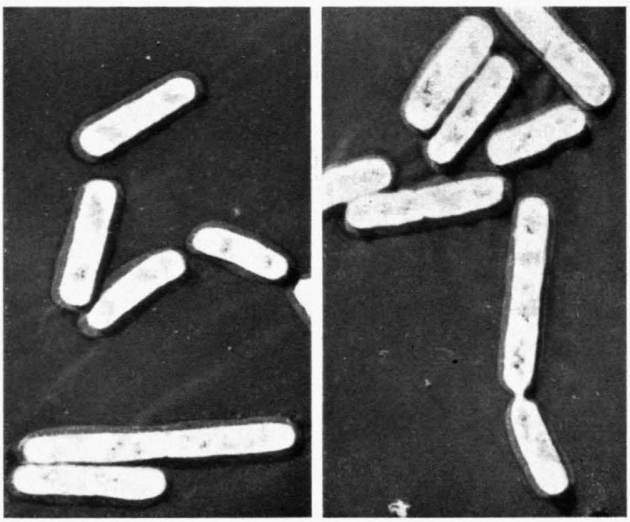

Abb. 18. D., Pepsin. Kerne aufgehellt, Einsenkungen der Kernzone an gewelltem Schattenverlauf erkennbar (Präparate waren vor der Bedampfung bereits mit Elektronen bestrahlt worden), Pd-bedampft, $5000 \times$.

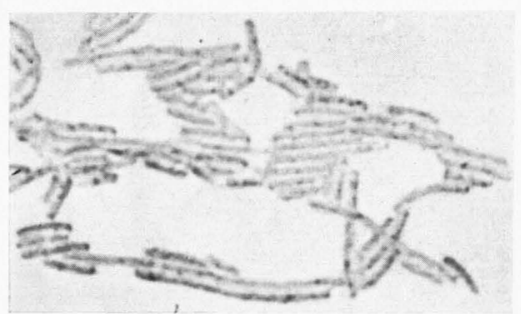

Abb. 19. R., D. Lichtoptisch, Giemsa. Kerne und Cytoplasma aufgehellt, unregelmäßige Struktur, $1500 \times$.

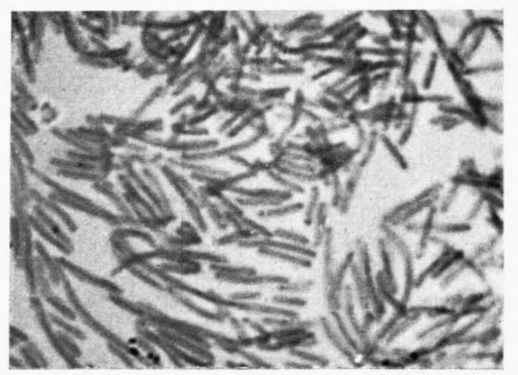

Abb. 20. R., D. Lichtoptisch, Lichtgrün. Homogene Färbung, intensiver als ohne Behandlung, $1500 \times$. 


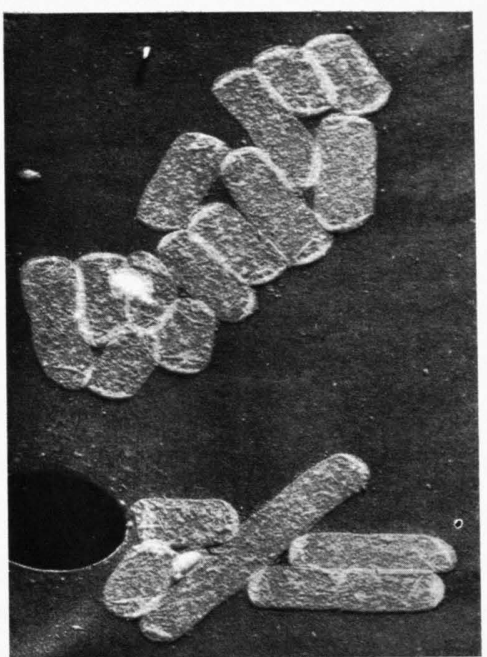

Abb. 22. R., D., Pepsin. Faltenbildung der Membranen an den Polen, 5000X.

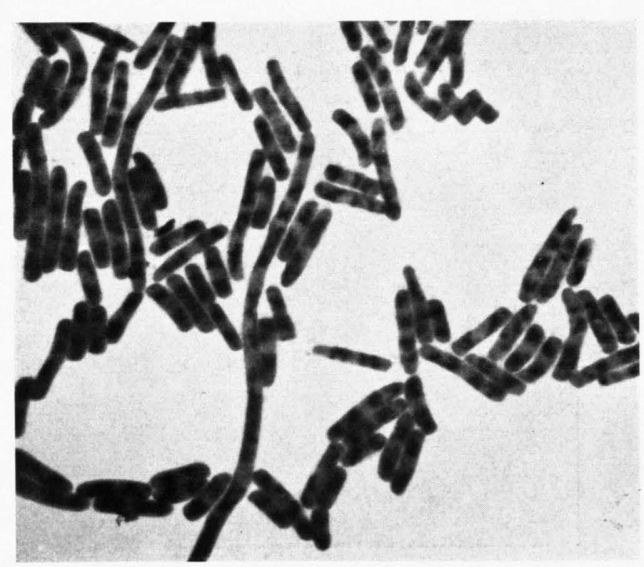

Abb. 23. R., n/100-HCl. Plasma mäßig aufgehellt, Kerne sichtbar, $2500 \times$.

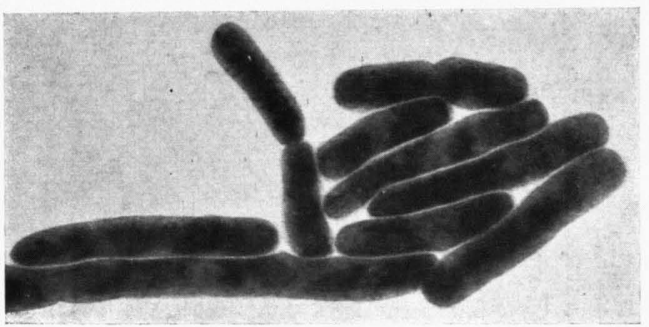

Abb. 24. R., D., n/100-HCl. Mäßige, uncharakteristische Aufhellung, $5000 \times$.

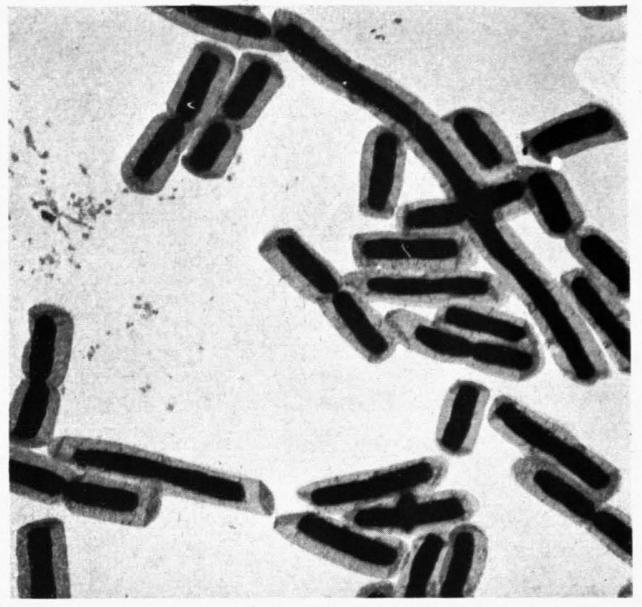

Abb. 25. Phosphatpuffer, Pepsin (je 1 Stde.); starke Retraktion des Cytoplasmas (fraglicher Abbau), deutlich sichtbare Membranen, $5000 \times$.

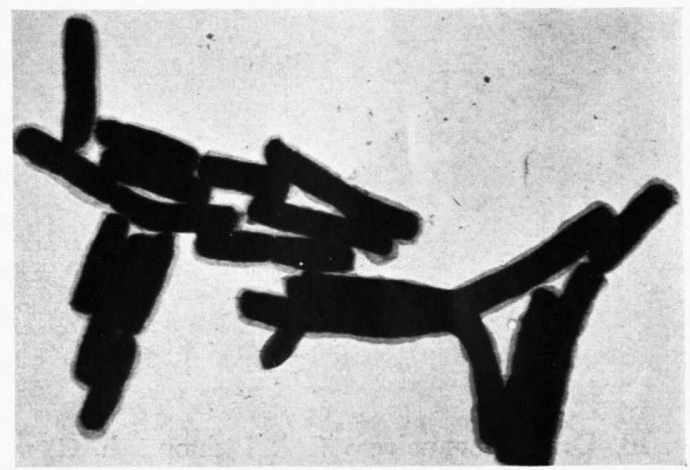

Abb. 26. Phosphatpuffer, n/100-HCl. Geringe Retraktion des Cytoplasmas, $5000 \times$.

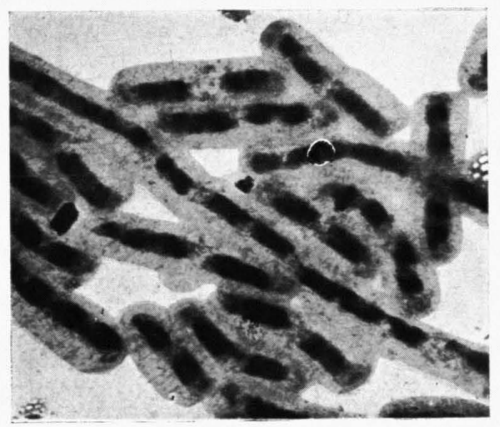

Abb. 27. R. $\left(0,2 \gamma / \mathrm{cm}^{3}\right)$, Pepsin. Cytoplasma im Inneren nicht völlig aufgehellt, Kerne noch durch Substanzbrücken verbunden, $5000 \times$. 


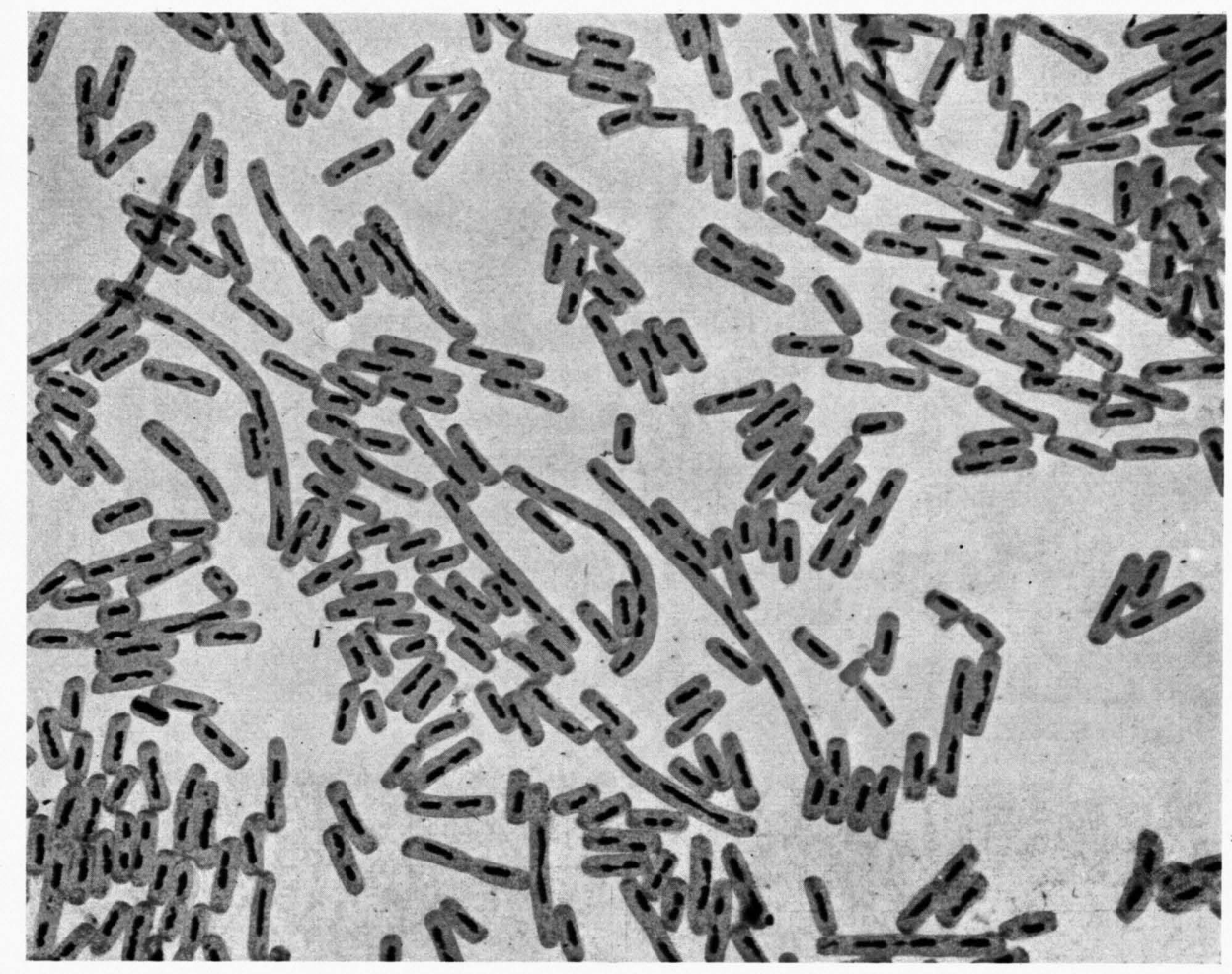

Abb. 11. R. $\left(20 \gamma / \mathrm{cm}^{3}\right)$, Pepsin. Cytoplasma aufgehellt, Kerne deutlich, $2500 \times$.

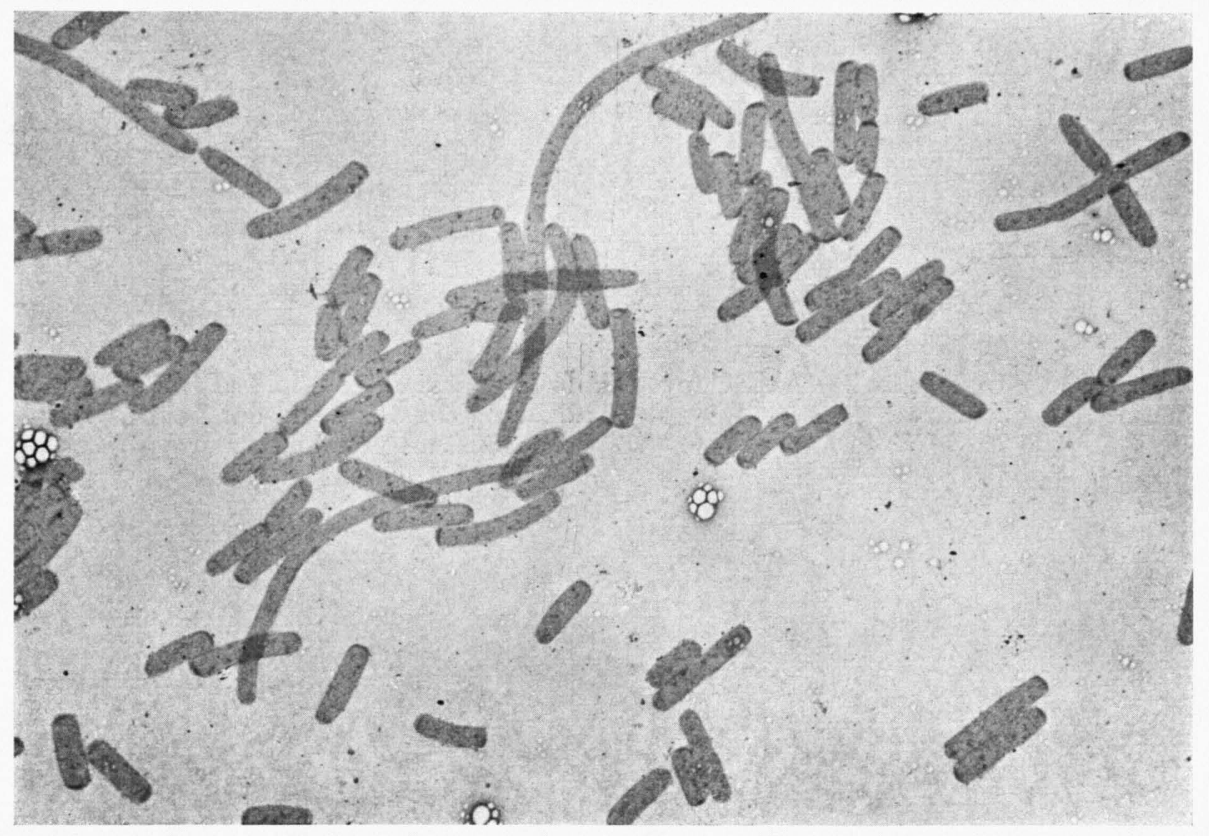

Abb. 21. R., D., Pepsin. Leere Membranen, $2500 \times$. 


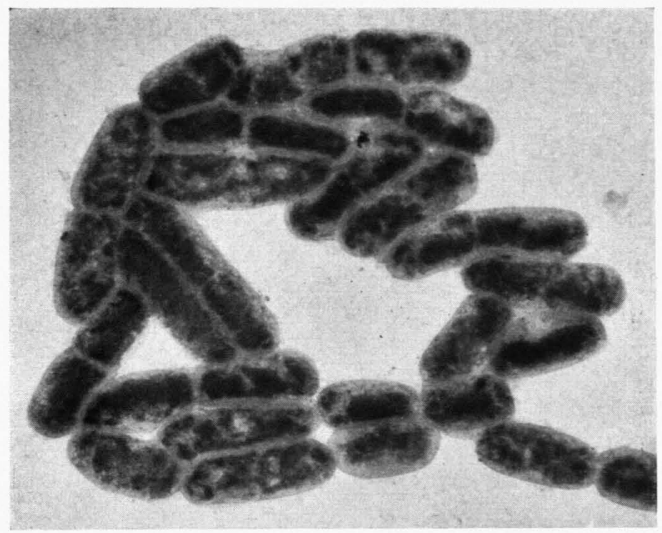

Abb. 28. R., D. (je $\left.0,002 \gamma / \mathrm{cm}^{3}\right)$, Pepsin. Uncharakteristische Aufhellung, beginnende Wirkung beider Nucleasen, $5000 \times$.

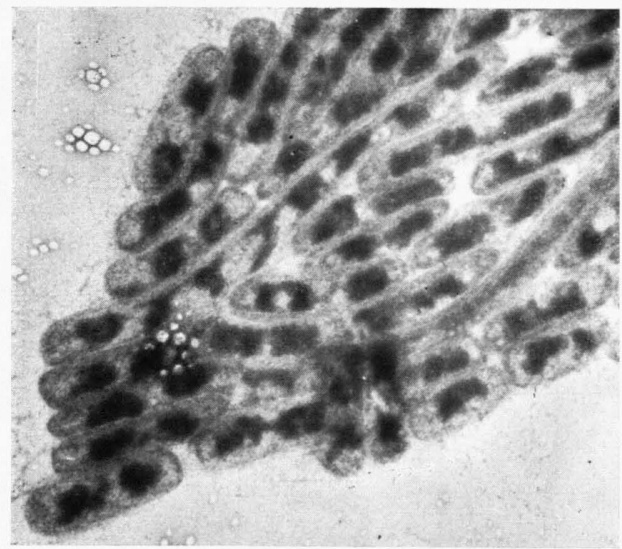

Abb. 29. R., Pepsin $\left(0,2 \gamma / \mathrm{cm}^{3}\right)$. Unvollständige Aufhellung des Cytoplasmas, Kerne sichtbar, $5000 \times$.

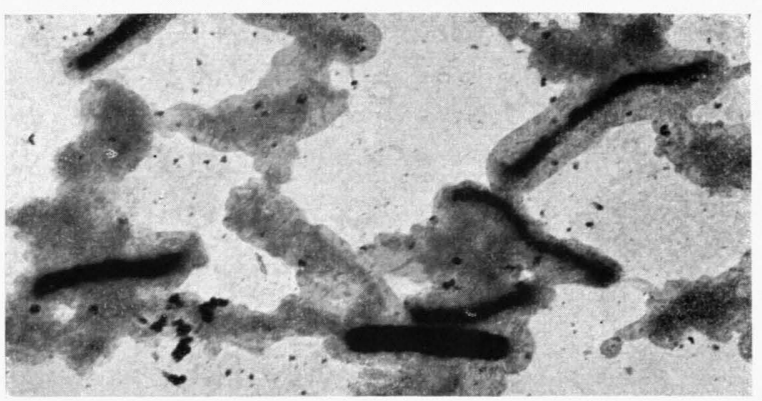

Abb. 30. Unfixiert, 20 Stdn. Lufttrocknung. R., D. (je $\left.20 \mathrm{\gamma} / \mathrm{cm}^{3}\right)$, Pepsin. Abbau ungleichmäßig, Membranen stark geschädigt, $5000 \times$.

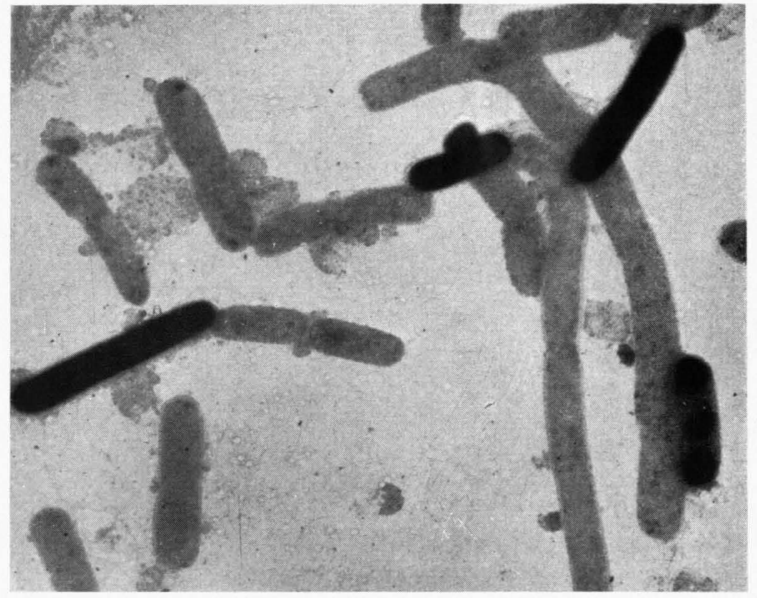

Abb. 31. Unfixiert, 15 Min. Lufttrocknung. Trypsin. Starke Aufhellung der Mehrzahl der Keime, Cytoplasmabegrenzung sichtbar, Membranen geschädigt, $5000 \times$. 
deren strukturellen und chemischen Aufbau als etwa Keime aus der Anlauf-(lag-)Phase oder ältere aus länger bebrüteten Kulturen. Orientierende Versuche an Bakterien aus 1 bzw. 4 Tage alten Kulturen, die sich in mancher Hinsicht anders verhielten, deuten auf die Wichtigkeit dieser Einschränkung hin.

Ältere Keime verhielten sich gegenüber Pepsin weniger resistent als junge. In der Pepsinresistenz junger Keime dürfen wir demnach nicht ohne weiteres einen Unterschied zwischen Bakterien und Quaderviren sehen. Letztere werden bekanntlich durch Pepsin partiell angegriffen 11, 38, 39 .

In Analogie zu den von Caspers on u.a. ${ }^{40}$ entwickelten Vorstellungen über die höhere Zelle haben wir - solange das Gegenteil nicht bewiesen ist - damit zu rechnen, daß nicht nur NS-, sondern auch Proteinzyklen existieren, daß demnach die Anteile an NS und Protein in dynamischem Fortschreiten verschiedene Zustände hinsichtlich ihres chemischen und ihres molekularen Aufbaues und hinsichtlich ihrer Bindung aneinander oder an andere Substanzgruppen durchlaufen. Dieser Wechsel wird sich in mindestens zweierlei Weise vollziehen: 1 . in dem von Malmgren und Hedén ${ }^{14}$ für die Gesamtkultur gesicherten Übergang von der lag- zur log- und schließlich zur stationären Phase, 2. innerhalb der einzelnen Keime der log-Phase im Rahmen der Karyound Cytokinese. Für letzteres fehlen unseres Wissens exakt deutbare experimentelle Hinweise noch völlig. Da naturgemäß die Entwicklungsstadien der Kernund Zellteilung nebeneinander vorkommen, kann dabei nur eine auf den einzelnen Keim zielende Analyse brauchbare Ergebnisse liefern. Wie C a s p e r s s o n ${ }^{41}$ selbst zum Ausdruck brachte ${ }^{42}$, sind Bakterien als Einzelobjekte der von ihm begründeten UV-Analyse kaum noch zugänglich, abgesehen davon, daß mit ihrer Hilfe allein auch keine Differenzierung von RNS und DNS erfolgen kann.

Wir halten es für möglich, daß die oben geschilderten Fixierungsversuche Hinweise auf derartige Entwicklungsstadien enthalten: Während die Fixierungen mit organischen Mitteln wie Chabaud- oder CarnoyGemisch, mit Äthanol, Methanol oder Formaldehyd zu einheitlichen Resultaten führten, ergab die Fer-

38 I. M. D a w s on u. A. S. M c F a r l a n e, Nature [London] 161, 464 [1948]; P. L é p in e, P. A t h a n a si u u. O. Crois s a n t, C. R. hebd. Séances Acad. Sci. 228, 1068 [1949].

39 D. Peters u. T. N a s e m a n n, Naturwiss. 39, 306 [1952].

40 T. C a s p e r s s o n, Cell Growth and Cell Function, New York 1950.

41 T. C a s p e r s s o n, Symposia Soc. exp. Biol. 1, 127 (s. S. 147) [1947]. mentbehandlung unfixierter oder $\mathrm{OsO}_{4}$-fixierter Präparate in frappantem Gegensatz dazu uneinheitliche Ergebnisse - sowohl licht- wie elektronenoptisch. Wir halten es für ausgeschlossen, daß diese Uneinheitlichkeit nur eine scheinbare ist, indem etwa die Organismen durch anhaftende Agarreste vor der Fermentbehandlung verschieden schnell trocknen oder unterschiedlich gegen die Fermente geschützt werden.

$\mathrm{Ob}$ es sich dabei um Unterschiede in der Membranpermeabilität, im Zellchemismus, beim unfixierten Präparat etwa noch um Enzyminhibitoren, eine Weiterentwicklung einzelner Keime, autolytische Veränderungen oder um eine Kombination solcher Effekte handelt, ist z. Zt. nicht zu entscheiden. Jedenfalls scheinen diese Eigenschaften bei Anwendung der organischen Fixierungsmittel einer "Gleichschaltung“ zu unterliegen, so daß hierbei das primär einheitliche Bild hervortritt, das bei den anderen Vorbehandlungen durch sekundäre Verschiedenheiten verdeckt wird. Im gegenwärtigen Stadium der Untersuchungen, die zunächst das methodische Vorgehen klären sollten, war es daher angezeigt, mit einem der organischen Fixierungsmittel zu arbeiten. Wir wählten wegen der guten lichtoptischen Erfahrungen auch anderer Autoren die Fixierung nach Chabaud.

Trypsin erwies sich hinsichtlich des Zellinhaltes als unspczifisch, da Cytoplasma und Kerne gleichermaßen abgebaut wurden. Die Zellmembran blieb ohne morphologisch faßbare Veränderung zurück. Der Abbau des fixierten Kernmaterials mit Trypsin steht in Einklang mit den früheren Unterșuchungen von C a spers s on u. a. ${ }^{43}, \mathrm{M}$ a zi a und J a e ger ${ }^{44}$ und Frovola ${ }^{45}$ über die tryptische Hydrolyse von Chromosomen höherer Zellen. Die Beobachtung eines uneinheitlichen Abbaues unfixierter Präparate nach kurzer Lufttrocknung und einer einheitlichen Hydrolyse nach längerer Trocknung entspricht der bekannten, von Northrop ${ }^{46}$ begründeten Vorstellung, daß lebende Zellen durch Trypsin nicht angegriffen werden.

$\mathrm{Da} ß \mathrm{~W}$ e i d e 147 bei seinen Abbauversuchen an E. coli mit Trypsin (M e r c k) in den Membranen noch unregelmäßige Innenkörper (Kernmaterial?) fand, erklärt sich wahrscheinlich durch seine andersartige Präparations-

42 „The bacteria are, however, so small that it is generally not possible to take absorption spectra thereof ". ${ }_{43}$ T. Caspersson, H. Hammarsten u. C. Hammarste n, Trans. Faraday Soc. 31, 367 [1935].

44 D. M a zi a u. L. J a e ge r, Proc. nat. Acad. Sci. USA 25, 456 [1939].

45 S. L. F rovol a, J. Heredity 35, 235 [1945].

46 J. H. N o r th r o p, J. gen. Physiol. 9, $497[1925 / 26]$.

$47 \mathrm{~W}$. W e id e l, Z. Naturforschg. 6 b, 251 [1951]. 
methodik. Bringmann ${ }^{6}$ beobachtete bei Bac.polymyxa nach Einwirkung von Trypsin (Merck) eine vollständige Aufhellung.

Pepsin - im $p_{\mathrm{H}}$-Optimum seiner Aktivität angewandt - griff Bakterien dieses Stadiums praktisch nicht an. Ein verschwindend kleiner Anteil (etwa 1\%) - wahrscheinlich degenerierte Keime der Einsaat war allerdings mehr oder weniger abgebaut, ohne das Gesamtbild bemerkenswert zu beeinflussen.

Úbereinstimmend mit den eingangs erwähnten Vorstellungen über die massenmäßig nur geringe Wirkung der Nucleasen (Depolymerisation des NS-Anteils) ist der von diesen Fermenten allein ausgehende elektronenoptische Effekt - im Gegensatz zu der sehr markanten Wirkung auf die Färbbarkeit — wenig eindrucksvoll. Die besonders bei Verwendung von R. beobachtete geringe Kontrastminderung zeigt, daß NS-Bruchstücke - vermutlich Oligonucleotide - aus dem Bakterienkörper herausgelöst werden, daß demnach eine Trennung von NS und Protein auch ohne Phosphatase erfolgt. Die NS-Spaltprodukte können offenbar die Bakterienmembran passieren, ein Verhalten, das dem der Spaltstücke tierischer NS gegenüber Kollodium- oder Zellophanmembranen 31, 48 durchaus entspricht ${ }^{49}$.

Tchan und Giuntini 51 sind die einzigen Autoren, die elektronenoptisch sichtbare Kerne nach Behandlung mit $\mathrm{R}$. allein beschrieben haben. Ihre Abbildungen sind allerdings wegen der geringen Zahl von Keimen und der sehr unklaren Kerndarstellung nicht überzeugend. Da sie keine näheren Angaben über das verwendete Fermentpräparat machen, ist bei ihnen die gleichzeitige Mitwirkung einer Protease nicht ausgeschlossen.

$\mathrm{Daß} n / 100-\mathrm{HCl}\left(p_{\mathrm{H}} 2\right)$ - als Kontrolle für die Pepsinhydrolyse - nach $\mathrm{R}$. angewendet eine geringe weitere Aufhellung zur Folge hatte, könnte zum Teil durch eine erleichterte Diffusion der Spaltstücke bedingt sein, da diese besonders gut säurelöslich sind $\$ 1,5 \%$.

Unsere entscheidende Beobachtung war, daß nach spezifischer Depolymerisierung der NS durch R. bzw. D. die zurückbleibenden Proteinanteile durch das sonst nicht angreifende Pepsin hydrolysiert werden können. Der Abbau der Nucleoproteide wird demnach

48 M. Kunitz, Science [New York] 90, 112 [1939].

49 Enzymatische Abbauversuche an nativem Nucleoproteid bakterieller Herkunft sind unseres Wissens bisher nicht durchgeführt worden. Das Verhalten der NS tierischer Herkunft kann natürlich nur unter Vorbehalt zur Deutung unserer Befunde herangezogen werden. S mith und Wy att 50 haben $\mathrm{z}$. B. eine unterschiedliche Zusammensetzung der DNS aus Bakterien und der höherer Organismen nachgewiesen.

50 J. D. S mith u. G. R. Wy att, Biochem. J. 49. 144 [1951]. durch die Nucleasen selektiv eingeleitet und durch die Proteolyse mit Pepsin unter Erhaltung der Spezifität vollendet. Für die ursprüngliche Resistenz gegenüber Pepsin ist demnach nicht der Aufbau der Proteinanteile verantwortlich - etwa in der Annahme, daß es sich dabei um üblicherweise pepsinresistente Protamine oder Histone handele - , sondern vielmehr deren Bindung an NS bzw. das Vorhandensein von NS überhaupt. Der Effekt stellt sich so dar, als ob DNS wie auch RNS einen Schutz gegenüber dem Angriff des Pepsins ausüben.

Nach den UV-Untersuchungen von $\mathrm{M}$ a $\mathrm{lm}$ g re $\mathrm{n}$ und $\mathrm{H}$ ed e n ${ }^{14}$ sinkt der NS-Gehalt der Keime mit zunehmendem Alter ab. Unsere Beobachtung, daß Pepsin ältere Keime angreifen kann, steht damit durchaus in Einklang.

$\mathrm{Ob}$ es sich bei der Schutzwirkung der NS um eine Wirkung auf das Enzym oder auf das Substrat handelt, ist z. Zt. nicht zu übersehen. Die Hemmung der Pepsinproteolyse durch NS scheint eine interessante Parallele in den kürzlich mitgeteilten Untersuchungen von $\mathrm{K}$ li n g e n b e r g ${ }^{53} \mathrm{zu}$ haben. Dieser Autor berichtete über eine gleichfalls durch NS verursachte Hemmung des katheptischen Eiweißabbaues. Er mißt der Ladungsänderung des Proteins durch Bindung an NS wesentliche Bedeutung bei. Bei Trypsin scheinen die Verhältnisse anders zu liegen (s. o.).

Auf lebende Bakterien, die im Gegensatz zu getrockneten und fixierten tryptisch nicht hydrolysiert werden, ließe sich evtl. ebenfalls eine Kombination von Nuclease und Trypsin mit Erfolg anwenden. Da aber mit der geringsten Denaturierung der Keime eine unspezifische Wirkung des Trypsins zu erwarten wäre (s. o.), verzichteten wir auf entsprechende Untersuchungen.

Die Spezifität der Nucleasen ist sehr ausgeprägt, besonders seitdem es $\mathrm{McD}$ on a ld ${ }^{\mathbf{1 9}}$ gelungen ist, letzte proteolytische Aktivitäten aus R. zu entfernen. $\mathrm{Z}$ a me $\mathrm{nh}$ of und $\mathrm{Ch}$ a r gaff $\mathrm{f}^{54}$ benutzten $\mathrm{z}$. B. R. für die Reinigung von DNS und D. für die von RNS (s. a. Gilbert u. a. ${ }^{55}$ ). Unsere Beobachtung einer scharfen Kernumgrenzung nach Anwendung von R. und Pepsin — auch nach längeren Einwirkungszeiten - bestätigt das.

51 Y. T. T ch a n u. J. Gi un tin i, Ann. Inst. Pasteur., Par. 77, 185, 188 [1949]; Proc. Conf. Electron Microscopy, Delft 1949, S. 159.

52 R. J. D u b o s, Science [New York] 85, 549 [1937].

53 H. G. K l in g e n b e r g, Hoppe-Seyler's Z. physiol. Chem. 290, 139 [1952].

54 S. Z a m e n h of u. E. C h a r g a f f, Nature [London] 168, 604 [1951].

55 L. M. Gillbe r t, W. G. Overend u. M. W e b b, Exp. Cell Res. 2, 138 [1951]. 
D a n i elli 56 erhob gegen die Anwendung von Enzymen für lichtoptisch-cytochemische Zwecke Einwände hinsichtlich ihrer Spezifität, die jedoch bei unseren Abbauversuchen durch die übereinstimmenden Ergebnisse bei verschiedenen Fixierungen und bei Zuhilfenahme ganz verschiedener Methoden nicht berechtigt wären. Ferner weist er darauf hin, daß es nicht sicher sei, ob die Enzyme im Einzelfall an das Substrat herangelangen könnten. Wir können in unserem Fall der Bakterienmembran - zum mindesten bei den beschriebenen Fixierungen mit organischen Flüssigkeiten - keinen hemmenden Einfluß zusprechen. Die Folgerung von D a nielli 56 , wegen der Möglichkeit von Fehldeutungen überhaupt auf die Anwendung von Enzymen für cytochemische Zwecke zu verzichten, halten wir daher nach unseren Erfahrungen für zu weitgehend.

Die Hydrolyse mit $n$ - $\mathrm{HCl}$ bei $60^{\circ}$ - der erste Schritt der Feulgenschen Nuclealreaktion und der HCl-Giemsa-Methode von Piekarski - führt auch elektronenoptisch zum gleichen Resultat wie die Anwendung von R. Da diese Behandlung RNS sehr viel schneller abbaut als DNS ${ }^{57}$, hat auch hierbei die nachfolgende Behandlung mit Pepsin eine Darstellung der Kerne zur Folge. Wegen der sicher besser ausgeprägten Spezifität der R. und wegen der bei höheren Temperaturen und zugleich stark saurem $p_{\mathrm{H}}$ unvermeidbaren Koagulationen möchten wir aber das Ferment nicht durch $n-\mathrm{HCl}$ ersetzen. Gleiche Überlegungen mögen Geltung haben für die Verwendung von Überchlorsäure, die von $\mathrm{C}$ a s s e ${ }^{58}$ sowie Graziosi und Pulvirenti59 in die Bakteriencytologie eingeführt wurde.

Nach Angaben von $\mathrm{Mudd}$ und $\mathrm{Smith} 60$ sowie $\mathrm{W}$ in k le r und $\mathrm{Kn}$ o ch 36 kann $n-\mathrm{HCl}$ allein zu einer elektronenoptischen Darstellung der Kernorte führen, wenn mit $\mathrm{OsO}_{4}$ fixiert wurde. $\mathrm{W}$ in k l e r 36 weist allerdings selbst auf die durch Gerinnungsvorgänge bedingten Artefaktmöglichkeiten hin. Immerhin scheinen diese Untersuchungen zu zeigen, daß nicht nur der NS-, sondern auch der Proteinanteil des Cytoplasmas nach ausreichender $\mathrm{OsO}_{4}$-Fixierung (Alkohol z. B. versagt) durch $n$-HCl hydrolysiert werden kann.

Ein recht brauchbarer Indikator für die Freilegung des Proteinanteils bietet sich in dem Farbstoff Lichtgrün. Die damit vorgenommene Färbung der intakten Bakterien ist sehr schwach. Nach Einwirkung von R., R. und D. oder $n-\mathrm{HCl}$, die durch Abbau der NS vermutlich basische Bindungen des Proteins freilegen, wird der saure Farbstoff erheblich besser gebunden, so daß es zu einer Intensivierung der Färbung kommt.

56 J. F. D a n i e l l i, Nature [London] 157, 755 [1946]; Symposia Soc. exp. Biol. 1, 101 [1947].

57 R. Vendrely u. J. Lipardy, C. R. hebd. Séances Acad. Sci. 223, 342 [1946].

58 W. A. C a s s e l, J. Bacteriol. 59, 185 [1950].
Die entsprechend geringeren Effekte nach Anwendung von D. allein werden allerdings nicht deutlich. Da die Farbintensität der Lichtgrünfärbung geringer ist als etwa die der normalen Giemsa-Färbung, ist das auch nicht zu erwarten. Die nachfolgende Behandlung mit Pepsin läßt nach $R$. und $D$. die Färbung erwartungsgemäß ausbleiben und führt nach $R$. oder $n$ - $\mathrm{HCl}$ zu einer Anfärbung der Kerne.

Unsere elektronenoptischen Ergebnisse stehen hinsichtlich der Kernorte und des Zellchemismus in ausgezeichneter Übereinstimmung mit den bisherigen lichtoptisch begründeten Vorstellungen (s. Übersicht von $\mathrm{P}$ i e karski${ }^{61}$ ). Es erhebt sich nun die Frage, wieweit die wiedergegebenen Kernstrukturen artefiziell verändert sind. Die Präparationsschäden beim Abklatschverfahren sind sicher sehr gering, um so mehr, als dabei auf jede Waschung verzichtet werden konnte. Kolloidchemische Veränderungen durch die Fixierungen, wie Entmischungen, Schrumpfungen, Quellungen usw., können wir aber nicht ausschließen. In Parallele zu lichtoptischen Untersuchungen 2, 3, 44 an höheren Zellen müssen wir zudem mit einer Volumenverminderung der Kernstrukturen rechnen, wenn nach R. noch Pepsin (im sauren Milieu) einwirkt. Ein Vergleich der lichtoptischen Abb. 9 und 10 weist in dieser Richtung. Allerdings könnte hierbei die durch Pepsin bedingte Eliminierung des Proteinanteils des Cytoplasmas auch durch Veränderung der optischen Verhältnisse zu einer nur scheinbaren Änderung der Kerngröße Anlaß geben. Wir müssen weiter den Vorbehalt machen, daß durch die spezifische Herauslösung von Strukturen anderes Material, das in diese eingebettet war, in unspezifischer Weise von seinem ursprünglichen Ort entfernt wird, und weiter, daß z. B. am Aufbau der Kernstrukturen auch RNS teilnimmt, wie es bei der höheren Zelle der Fall ist. All dieser Gründe wegen verzichten wir im gegenwärtigen Stadium unserer Untersuchungen auf eine Deutung der beobachteten Strukturen. Wir sind aber nicht im Zweifel, daß die Polymorphie der elektronenoptisch sichtbar gemachten Kerne einen Hinweis auf die Dynamik der Kernveränderungen im Verlauf der Kern- und Zellteilung enthält. Wir glauben ferner, daß es mit Hilfe der beschriebenen Methode unter Erarbeitung noch schonenderer Fixierungs- und Auftrocknungsbedingungen möglich sein wird, der im

59 F. Graziosi u. G. B. Pulvirenti, Boll. Soc. ital. Biol. sperim. 26, 962 [1950].

60 S. M udd u. A. G. S mith, J. Bacteriol. 59, 561 [1950].

61 G. Pi e k a r ski, Ergebn. Hyg., Bakteriol., Immunitätsforsch. exp. Therap. 26, 333 [1949]. 
lebenden Zustand vorhandenen Kernstruktur der Bakterien elektronenoptisch näher zu kommen und insbesondere die von DeLamater und $\mathrm{Mudd}^{30}$ angeschnittene Frage einer Kernteilung durch Mitose bei Bakterien einer Lösung zuzuführen.

Auch von einer Deutung „unspezifischer“ Veränderungen unter verlängerter Einwirkung der Kontrollösungen möchten wir Abstand nehmen. Die Tatsache, daß man sowohl licht- wie elektronenoptisch mit derartigen Veränderungen durch die Lösungsmittel der Enzyme rechnen muß, weist auf die Notwendigkeit hin, regelmäßige Kontrolluntersuchungen durchzuführen, die Einwirkungszeiten der Enzyme möglichst kurz zu halten und nicht über Brutschranktemperatur hinauszugehen.

Vergleichsuntersuchungen an einem zweiten Stamm von E. coli führten zu völlig gleichartigen Ergebnissen. Allerdings waren hier bereits ohne Vorbehandlung die Kernzonen als Aufhellungen elektronenoptisch erkennbar (s. o.). Da die Kern- und Membran-

62 G. B r in g m a n n, Z. Hyg. Infektionskrankh. 134, 219 [1952].

63 G. P i e k a r s k i, Zbl. Bakteriol., Parasitenkunde Infektionskrankh., Abt. I, Orig. 142, 69 [1938]. verhältnisse bei verschiedenen Stämmen der gleichen Spezies (E. coli ${ }^{62}$ ) sowie verschiedenen verwandten Arten ${ }^{22,}{ }^{63}$ weitgehend ähnlich sind, läßt sich diese Methode wahrscheinlich auch auf andere gramnegative Bakterienspecies übertragen. Wieweit sie darüber hinaus anwendbar ist, muß künftigen Untersuchungen vorbehalten bleiben.

Da die lichtoptischen Verfahren einschließlich der Ultraviolettmikroskopie für eine auf den einzelnen Keim gerichtete Untersuchung kleiner Bakterien kaum noch geeignet sind und da sie für den Bereich der Virusarten überhaupt entfallen, scheint uns diese Methode besondere Perspektiven für cytologische Untersuchungen kleinster Organismen zu eröffnen. Wir zweifeln nicht daran, daß die Kombination von Nucleasen und Proteasen auch bei der elektronenoptischen Bearbeitung anderer biologischer Substrate brauchbar ist. Voraussetzung für eine erfolgreiche Anwendung wird aber sein, daß ein subtiles Studium der Fixierungsfolgen damit verbunden wird.

Wir danken den Herren Boldt, Geister und $\mathrm{G}$ i e s e für ihre experimentelle Mitarbeit.

\title{
Untersuchungen an Spechten zur Frage der funktionellen Anpassung an die mechanische Belastung
}

\author{
Von Fritz Becher \\ Aus der Medizinischen Universitätsklinik und Poliklinik, Tübingen \\ (Z. Naturforschg. 8 b, 192-203 [1953]; eingegangen am 1. Dezember 1952)
}

Der Schädel des Spechtes und sein Inhalt sind durch das Hämmern am Stamm einer dauernden mechanischen Belastung ausgesetzt. Anatomisch finden sich folgende Struktureigentümlichkeiten, die als eine Adaptation an die mechanische Belastung angesehen werden können:

1. Federnde Verbindung des Schnabelschädels mit dem Hirnschädel, wobei die Stoßwirkung vor allem durch das stark entwickelte und fest eingefügte Quadratum aufgefangen und in eine Torsionswirkung umgewandelt wird.

2. Steilstellung der Schädelbasis.

3. Fehlen der winkligen Abknickung zwischen Hirnstamm und Vorderhirn.

4. Geringe Ausbildung der Rinde. Verteilung der Ganglienzellen in einem Geflecht von Markfasern.

(Der unter 1. genannte Mechanismus ist beim Specht besonders ausgebildet, 2. bis 4. allen Vogelarten gemeinsam.)

Die Art der mechanischen Beanspruchung wird an Hand von Magnetophonbandaufnahmen eines hämmernden Spechtes analysiert. Es handelt sich um eine Klopfserie von etwas über 1/2 sec Dauer und 18-22 Hz Frequenz. Die Frequenz nimmt im Laufe der Klopfserie zu, die Amplitude ab. Es wird hieraus der Schluß gezogen, daß ein Abfederungsmechanismus eine Rolle spielt.

Zum Schluß wird auf Analogien des Verhaltens von Amplitude und Frequenz bei der Klopfserie des Spechtes und beim Klonus der Muskulatur des Menschen hingewiesen.

Es wird daraus die Hypothese abgeleitet, da $\beta$ die Schlagfolge des Hämmerns nach Art einer willkürlich gebahnten Reflexreihe abläuft und daß reflektorische Mechanismen in der bei der Führung des Schnabelstoßes tätigen Muskulatur modifizierend zur Auswirkung kommen, wodurch das Auftreten einer über das physiologische Maß hinausgehenden Belastung verhindert wird. 